\title{
Da Filosofia APLICAda Às NECESSIDAdeS FILOSÓFICAS DAS PESSOAS, NAS EMPRESAS E ORGANIZAÇÕES. JUSTIFICAÇÃO DO PAPEL DO CONSULTOR FILOSÓFICO ${ }^{1}$
}

\section{ON PHILOSOPHY APPLIED TO PHILOSOPHICAL NEEDS OF PEOPLE IN COMPANIES AND INSTITUTIONS. JUSTIFICATION OF THE ROLE OF PHILOSOHICAL COUSELOR}

\author{
JOANA SouSA \\ Instituto Universitario ISLA \\ joanarssousa@gmail.com
}

RECIBIDO: 25 DE MAYO DE 2012

ACEPTADO: 1 DE NOVIEMBRE DE 2012

Resumen: Este artigo estuda as bases da Filosofia Aplicada dentro das empresas e organizações. Assim, aprofunda nas necessidades filosóficas dos trabalhadores que trabalham nessas instituições e propõe uma metodologia de trabalho para o consultor filosófico baseado nas suas descobertas.

Palabras clave: consultor filosófico, empresas, necessidades filosóficas

\begin{abstract}
This paper Studies Philosophical Practice ground developed inside companies and institutions. So, it deepens in philosophical necessities of employees of those institutions. In addition, it is proposed a specific methodology based on its discoveries.

Keywords: philosophical counsellor, companies, philosophical needs.
\end{abstract}

\section{Introdução}

Pertinência do estudo

Um problema filosófico tem a seguinte forma: “Não me sei orientar"²

Da licenciatura de Filosofia ficou uma questão a resolver: o que fazer com este diploma? A vida profissional afastou-nos do amor à sabedoria ${ }^{3}$, mas a academia

\footnotetext{
${ }^{1}$ Este trabajo constitui parte da teses de maestrado da candidata Joana Sousa. Foi dirigida pelo Profesor José Barrientos y defendida em fevereiro de 2012.

2 WITTGENSTEIN Ludwig. - Tratado Lógico-filosófico.Investigações Filosóficas. - Lisboa: Fundação Calouste Gulbenkian, 1995, 2ª edição. - p. 261
} 
soube aproximar-nos da Filosofia. A propósito de uma investigação sobre consultoria espiritual ${ }^{4}$, encontramos referências a "aconselhamento filosófico", "orientação" ou "consultoria filosófica". Nessa altura, tornam-se familiares os nomes de Lou Marinoff, Peter Raabe, Tim LeBon e Óscar Brenifier. E a curiosidade aumenta: será possível imprimir um dinamismo outro ao filósofo, que vá para lá do espaço de sala de aula ou da investigação teórica?

Pode a Filosofia conhecer aplicações práticas? Em 1980 Seymon Hersh escreve um texto intitulado The Counselling Philosopher ${ }^{5}$ inaugura o momento em que se reconhece o papel do filósofo como conselheiro ou consultor. Gerd Achenbach, autor de Philosophische Praxis ${ }^{6}$ inicia a prática da consulta filosófica em 1981. Um ano depois fundou a Associação Alemã para a Prática Filosófica, que se tornou, em 1998 na Internationalen Gesellschaft fur Philosophische Praxis (IGPP).

Los términos "philosophical counselling" e "philosophical practice" van a ser la traducción de "Philosophisce Praxis und Beratung" de Gerd Achenbach ${ }^{7}$

De "Philosophisce Praxis und Beratung" derivam as expressões filosofia prática, orientação filosófica e aconselhamento filosófico ${ }^{8}$; a sua tradução literal é

\footnotetext{
${ }^{3}$ «(...) Pitágoras teria sido o primeiro a utilizar a palavra filósofo e filosofia (...) para significar que o nome de sábio só a Deus convém, devendo os homens contentar-se com amar e perseguir a sabedoria. (...) Com Platão, a palavra filosofia adquire vida autónoma e acede a uma dignidade nunca dantes imaginada. Ao sentido meramente literal de amor da sabedoria, Platão acrescenta-lhe o sentido paradoxal da ciência da ignorância ou saber do não saber, porque o filósofo nem de todo sabe nem de todo não sabe, vivendo numa situação intermédia entre a ignorância absoluta da sabedoria e a sua posse plena.» FREITAS Manuel da Costa, Filosofia - Logos Enciclopédia Luso Brasileira de Filosofia, Lisboa: Editorial Verbo, 1991, vol. 4, pp. 576-577

${ }^{4}$ Dessa investigação resultou o nosso trabalho: SOUSA, Joana - Da inteligência intelectual à inteligência espiritual - proposta de perfil de competências espirituais do consultor - projecto desenvolvido no âmbito da Pós Graduação de Consultoria de Empresas, ISLA, 2005/06. A denominação de «consultor espiritual» tem como base a obra de Dan e Ian ZOHAR, QS Inteligência Espiritual - São Paulo: Editora Record, 2000.

Cfr., ainda, o ponto 2.4. do presente trabalho.

No Anexo B apresentamos a nossa proposta de perfil de consultor filosófico, com base nesse trabalho realizado em 2006. Durante a realização desta tese, revimos o trabalho apresentado nessa altura.

5 SCHUSTER Shlomit C. - The Meaning of Philosophical Counseling - [On-Line] 1996, [24.10.2010]. http://sites.google.com/site/thephilosophicalcounselingweb/publication-list/themeaning-of-philosophical-counseling

Jose Barrientos Rastrojo também faz referência a este artigo. Cf. BARRIENTOS RASTROJO Jose. Introducción al Asesoramiento y la Orientación Filosófica. - Santa Cruz de Tenerife, Ediciones Idea, 2005. - p. 20

${ }^{6}$ Esta obra foi publicada em 1984, tendo conhecido a sua segunda edição em 1987.

${ }^{7}$ BARRIENTOS RASTROJO Jose. - Op. Cit. - p. 21

${ }^{8}$ «Philosophy is seen as an ongoing dialogue with life and reality, rather than as a theoretical
} 
prática e consulta filosófica. Actualmente, usam-se as expressões filosofia prática ou filosofia aplicada.

Mas que sentido faz a existência de um filósofo prático ${ }^{9}$ nos dias de hoje? O que faz com que as pessoas procurem um filósofo? E que sentido ${ }^{10}$ fará isso numa empresa ou organização $(\mathrm{E} / \mathrm{O}) ?^{11}$

They visit a Philosophical Practice in order to understand and to be understood. It is almost never the Kantian question "How shall I live" which moves them, but more often the question of Montaigne: "What am I actually doing"? ${ }^{12}$

Um pouco por todo o mundo, os filósofos passaram a constar, por exemplo, de comissões de ética. Actuam na emissão de pareceres, assumindo o ponto de vista filosófico sobre deliberações. O filósofo proporciona o diálogo, permitindo o treino do uso de técnicas filosóficas, por exemplo, no processo de tomada de decisão. Nigel Laurie ${ }^{13}$ questiona-se: será que a culpa de tudo isto é de Sócrates, o ateniense que se passeava pelas ruas de Atenas, promovendo o diálogo? Em 1929 Leonard Nelson publica um texto de nome Die sokratische Methode e que visa reformular e reavivar a Filosofia. O seu modelo de diálogo socrático apresenta procedimentos rigorosos adoptados nas organizações. ${ }^{14}$

Francisco Barrera ${ }^{15}$ aponta para a necessidade de procurar novos caminhos e de mudar de atitude, ao nível das E/O. Tal mudança implica a transformação dos modelos organizativos, no sentido da diminuição do automatismo e aumento da espontaneidade. Neste âmbito, Barrera menciona o trabalho de Daniel Goleman sobre a Inteligência Emocional ${ }^{16}$. A redução da acção humana à

construction of abstract theories about life and reality. The idea is that individuals encounter basic philosophical life-issues throughout their lives, and the role of philosophical counseling is to help them deal with these issues more fully.». LAHAV Ran. - The Efficacy of Philosophical Counselling: A fisrt outcome study. - The Benefits of Philosophy in Practice. - Practical Philosophy. Journal of the Society for Philosophy in Practice.- 2001, vol. 4, nº 2, p. 5.

${ }^{9}$ Em inglês: philosophical practitioner.

${ }^{10}$ Sobre o trabalho, a saúde e a filosofia leia-se o dossier AA.VV. - Le travail nuit-il à la santé?, publicado na Philosophie Magazine, $\mathrm{n}^{\mathbf{0}}$ 39, 2010.

${ }^{11}$ De ora em diante utilizaremos E/O para nos referirmos a empresas ou organizações.

12 ACHENBACH Gerd. - A short answer to the question: What is Philosophical Practice?. - [OnLine] [17.11.2010] http://www.igpp.org/eng/philopractice.asp

${ }_{13}$ Cfr. LAURIE Nigel - Philosophie goes to Work. - Thinking Through Dialogue. - Practical Philosophy Press, 2001, pp. 192-194.

${ }^{14}$ Cfr. NELSON, Leonard. - El método socrático. - Cádiz: Huqualya,, 2008, bem como, do mesmo autor, Socratic method and critical Philosophy. - Nova Iorque: Delected Essays, 1965

15 BARRERA Francisco. - Su empresa puede estar necesitando un filósofo. - La filosofia a las puertas del tercer milénio. - Sevilha: Fénix Editora, p. 165.

${ }^{16}$ Durante décadas, as organizações acreditavam que as emoções prejudicavam o profissionalismo, o raciocínio e que deviam ficar restritas às vidas e cada indivíduo. O novo paradigma passa por saber 
produção e o esquecimento das actividades especificamente humanas tem como consequência a existência de $\mathrm{E} / \mathrm{O}$ onde o colaborador não conhece a finalidade, nem sequer o sentido do seu trabalho. O Homem é, enquanto trabalhador, arrancado da sua própria humanidade. ${ }^{17} \mathrm{Na}$ empresa, o filósofo proporciona uma reflexão sobre a cultura empresarial, criando um espaço para a pergunta sobre a forma de fazer as coisas. ${ }^{18}$

\section{Questão de partida e objectivos}

Pretendemos saber de que forma pode o consultor filosófico contribuir com um olhar distinto no seio das E/O. Perguntamos: no âmbito das E/O, as pessoas apresentam necessidades filosóficas?

Avançamos com a hipótese de que, sim, os recursos humanos das E/O apresentam necessidades de índole filosófica. Para isso, propomo-nos a

- definir que necessidades filosóficas são essas e;

- procurar a sua identificação numa dada população.

O passo seguinte seria o de afinar a construção do perfil de competências ${ }^{19}$ para o consultor filosófico, passo que ficará adiado para uma futura investigação.

como lidar com as emoções, em vez da preocupação em saber se as mesmas são positivas ou negativas e controláveis.

Sobre esta temática aconselhamos a leitura de alguns artigos como GARDNER Howard. - Using Multiple Intelligences to Improve Negotiation Theory and Practice - Negotiation Journal; Oct 2000; 16, 4; ABI/INFORM Research, pp. 321-324; bem como a obra de Daniel GOLEMAN, Trabalhar com inteligência emocional (Lisboa. Temas e Debates, 2005, $3^{\mathrm{a}}$ edição).

No Anexo A apresentamos um mapa-resumo dos autores e teorias relacionadas com a Inteligência Emocional.

Aproveitamos para referir o trabalho do português António DAMÁSIO: «Conhecer a relevância das emoções nos processos de raciocínio não significa que a razão seja menos importante do que as emoções, que deva ser relegada para segundo plano ou deva ser menos cultivada. Pelo contrário, ao verificarmos a função alargada das emoções, é possível realçar os seus efeitos positivos e reduzir o seu potencial negativo. Em particular, sem diminuir o valor da orientação das emoções normais, é natural que se queira proteger a razão da fraqueza que as emoções anormais ou a manipulação das emoções normais podem provocar no processo de planeamento e decisão. ( $O$ Erro de Descartes. Emoção, Razão e Cérebro Humano. - Lisboa: Publicações Europa América, 2003, 23ª edição p. 252) ${ }^{17}$ BARRERA Francisco - Art. Cit., p. 166.

${ }^{18}$ Tivemos oportunidade de defender esta ideia no \#6 Ignite Portugal, a 16 de Junho de 2010, com uma apresentação intitulada http://www.youtube.com/watch?v=T4OXgweJT3Y [16.01.2011]

${ }^{19}$ Conforme indicámos na nota $\mathrm{n}^{\circ} 3$, desenvolvemos um trabalho onde avançamos com uma proposta de perfil de consultor «espiritual», que na altura definimos, também, como consultor filosófico. Remetemos esta proposta para o Anexo A do presente projecto. Realizamos, entretanto, algumas alterações face à versão presente no projecto da Pós-graduação. Consideramos que poderemos apresentar esse perfil revisto e melhorado, com base nos resultados obtidos durante esta investigação. 
Pretendemos reunir alguns instrumentos de trabalho para o consultor filosófico, no que respeita ao levantamento das necessidades filosóficas junto dos recursos humanos, nas empresas e organizações.

\section{Contributo académico}

O caminho das Novas Práticas Filosóficas (NPF) ${ }^{20}$ tem vindo a conhecer a consolidação junto da academia. Registamos alguns contributos investigativos: Peter Raabe é o autor da primeira tese de doutoramento na área da filosofia prática; Jose Barrientos Rastrojo conclui, em 2009, em Espanha, uma tese de doutoramento intitulada Vectores Zambranianos para una Teoría de la Filosofía Aplicada a la Persona ${ }^{21 .}$ Em Portugal existem já algumas teses de mestrado na área da Filosofia para Crianças22 e surgem ecos que anunciam trabalho

\footnotetext{
${ }^{20}$ De ora em diante, utilizaremos NPF para designar Novas Práticas Filosóficas.

As NPF abrangem duas grandes áreas: a filosofia para crianças e a consultoria filosófica. A primeira tem origem no programa que o Professor Matthew Lipman concebeu nos anos 60: «Professores de qualquer disciplina preocupam-se quando seus alunos apenas memorizam os conteúdos pelos quais serão testados e não aprendem a pensar numa disciplina. (...) a filosofia é a disciplina cuja forma e pedagogia são uma só coisa. Até onde isto for assim - que a forma dialética da filosofia é idêntica à sua pedagogia -, a filosofia fornece um modelo formidável para o processo educacional como um todo.» Matthew LIPMAN. - A Filosofia vai à Escola. - São Paulo: Summus Editorial, 1998, p. 4753.

O Professor Lipman faleceu no passado dia 26 de Dezembro de 2010 e deixa-nos um legado bastante rico na área da filosofia para crianças, e não só. Isto porque as metodologias que o Professor defendeu como fundamentais em termos de competências críticas, criativas e éticas perpassam muito daquilo que se escreve e se defende a propósito da filosofia nas $\mathrm{E} / \mathrm{O}$ e outras áreas em que se procura levar a Filosofia ao «cidadão comum».

Desde 2008 que desenvolvemos investigação e trabalho na área da Filosofia para Crianças; ainda assim, os nossos primeiros passos aconteceram no âmbito da consultoria filosófica, com a apresentação de comunicação no III Encontro Português de Filosofia Prática» - Congresso Português de Ética Aplicada, 23 e 24 de Outubro de 2006, UCP (Porto), com comunicação denominada Perfil de Competências de Consultor Espiritual nas Empresas e nas Organizações. Foi neste Congresso que tive a oportunidade de conhecer pessoalmente aquele que viria a ser o orientador do presente trabalho, o Professor Jose Barrientos Rastrojo, bem como o Professor Lou Marinoff.

${ }^{21}$ BARRIENTOS RASTROJO Jose. - Vectores Zambranianos para una Teoría de la Filosofía $\begin{array}{llllll}\text { Aplicada } & a & l a & \text { Personar } & - & \text { [On-Line] [08.12.2010] }\end{array}$ http://fondosdigitales.us.es/tesis/tesis/1010/vectores-zambranianos-para-una-teoria-de-la-filosofiaaplicada-la-persona/

${ }_{22}$ A título de exemplo, indicamos dois trabalhos: ASSUNÇÃO Susana da Conceição Maio. Filosofia com Crianças e Jovens - uma proposta de Educação do pensar como um lugar-comum. Faculdade de Letras da Universidade do Porto, Novembro de 2010 [On-Line] [29.01.2011] http://sigarra.up.pt/flup/teses_posgrad.tese?P_SIGLA=MEFIL\&P_ALU_NUMERO=080739062\&P_ LANG=0 e LIMA Denise Maria Domingues de. - Filosofia para crianças : uma abordagem crítica dentro da filosofia da educação - [On-Line] 2004 [15-09-2008] http://repositorium.sdum.uminho.pt/handle/1822/4925
} 
académico na área da consultoria filosófica. Com o presente trabalho, pretendese dar um contributo académico, uma primeira sustentação teórica fundamentada, para uma área da Filosofia que se apresenta como prática e/ou aplicada. Ainda que pouco trabalhada no seio académico, a aplicação da Filosofia aos meios empresarial e organizacional é, já, referida como vantajosa nalgumas revistas da área da gestão. ${ }^{23}$ Em 2010 a Universidade de Sevilha concedeu um prémio à empresa FAME, no âmbito de um concurso de iniciativas empresariais da Universidade. ${ }^{24} \mathrm{Na}$ revista Pessoal ${ }^{25}$, Paulo Morgado afirma que "A Filosofia parece uma coisa éterea para quem não a conhece. A Filosofia, designadamente nas suas componentes mais lógicas e de linguagem, oferece-nos excelentes ensinamentos que podem ser utilizados nas empresas. Vou-lhe dar um exemplo: a linguagem que se utiliza dentro de uma organização." Paulo Morgado refere a questão da linguagem e de como a falta de consciência daquilo que estamos efectivamente a dizer pode afectar e/ou dizer algo sobre a organização em si.

\section{Estrutura do trabalho}

O trabalho encontra-se dividido em seis capítulos: o capítulo I introduz-nos à temática e à sua relevância enquanto elemento de investigação académica; o capítulo II diz respeito à revisão de literatura, no qual abordamos a temática da filosofia aplicada no seio empresarial/organizacional; é neste capítulo que desenvolvemos a questão do perfil do consultor filosófico e das necessidades filosóficas das pessoas que se constituem enquanto recursos humanos. No capítulo III apresentamos o nosso modelo de análise e no capítulo IV a metodologia científica escolhida para o tratamento deste tema. O capítulo V é dedicado à apresentação dos resultados da aplicação das metodologias. $\mathrm{O}$ capítulo VI encerra este trabalho, apresentando as conclusões do mesmo, bem como as recomendações para o futuro.

\footnotetext{
${ }^{23}$ Cfr. PEREIRA Joana Madeira. - Pensamentos (úteis) para a arte de gerir. - Exame, nº320, Dezembro de 2010,

${ }^{24}$ http://filosofia-aplicada.blogspot.com/2010/06/entrega-de-premio-la-empresa-de.html [On-Line] [14-08-2011]

Pode ler-se ainda este artigo sobre a Filosofia e o seu caminho da caverna platónica às empresas: http://filosofia-aplicada.blogspot.com/2010/08/entre-filosofia-aplicada-y-universidad.html [On-Line] [14-08-2011]

25 Cfr. CARREIRA Duarte Albuquerque - Faz falta Filosofia na Gestão RH. - Pessoal, n 102, Abril de 2011 .
} 


\section{Revisão de literatura}

\section{Filósofo nas E/O?- Da mudança ao diálogo}

This is a world of movement, tension, and conflict, balanced by rewards for the small, skilled, flexible, and technologically aware organizations that succeed by working in harmony and partnership with a wide and shifting selection of other organizations from across the world. This is a world of migration and conflict for the technologically poor, and one of small cluster organizations, high skill, and mobility, and longevity for the technological elite. This will affect us allinfluencing our jobs and our security - and also our morality. As we prepare our students to become HR professionals, academics, and managers we should be anticipating what their future needs will be: preparing them for the future, not the past. To do our jobs properly we have to look at the wider picture ${ }^{26}$

Hoje em dia, as E/O vivem a mudança ${ }^{27}$ de uma forma profundamente rápida, confrontando-se frequentemente com momentos de crise. ${ }^{28}$ A mudança é algo que a maioria das pessoas teme no seu local de trabalho: "Uma mudança rápida, até vertiginosa, e quase constante parece estar a acontecer à nossa volta em todos os sectores da economia." 29 Mas já Heraclito de Éfeso, um dos primeiros filósofos, falava da mudança (o devir), considerando-a como a única coisa constante no nosso mundo. ${ }^{30}$ Ainda assim, foi o pensamento de Parménides que

${ }^{26}$ LEE Monica. - Human Resource Development from a Holistic Perspective. - Advances in Developing Human Resources [On-Line] 2007, vol. 9, $\mathrm{n}^{\circ} . \quad 1, \quad$ p. 106 [27.04.2009] http://adh.sagepub.com/cgi/content/abstract/9/1/97

${ }_{27}$ «A gestão da mudança de sucesso requer uma abertura a problemas e soluções inesperadas, porque é nessa abertura que reside a essência precursora do novo desenvolvimento.» MORGAN Gareth, ZOHAR Asaf. - Atingindo a mudança quântica: Incrementalmente! - Empresas, Caos $e$ Complexidade, Lisboa: Editora RH, 2001, p. 201 A mudança é uma variável constante: «A gestão da mudança organizacional é um tema contemporâneo amplamente investigado (Cunha et al, 2007). A mudança acabou por se transformar numa variável constante no cenário económico e social das últimas décadas do século XX e início do século XXI acentuando uma paisagem competitiva feroz, turbulenta, onde tudo se desenrola a grande velocidade, o que imprime um carácter cada vez imprevisível na mudança (Huber e Glick, 1993; Bettis e Hitt, 1995; Cunha e Rodrigues, 2002).» SANTOS Alexandra. - Mudar as organizações, mudar as pessoas: O Impacto da Mudança nas Competências Individuais. - Dissertação para a obtenção do grau de Mestre em Gestão re Recursos Humanos, Lisboa, 16 de Julho de 2011, p. 8.

${ }^{28}$ Cfr. WANG Jia, HUTCHINS Holly M., GARAVAN Thomas N. - Exploring the strategic role of human resource development in organizational crisis management. - Human Resource Development Review [On-Line] 2009, pp. 21 - 53 [29.04.2009] http://hrd.sagepub.com/cgi/content/abstract/8/1/22

${ }^{29}$ MORRIS Tom. - Se Aristóteles fosse Administrador da General Motors. - Lisboa: Publicações Dom Quixote, 2009, p. 150.

${ }^{30}$ KIRK G. S., RAVEN J. E., SCOFIELD M. - Os filósofos pré-socráticos. - Lisboa: Fundação Calouste Gulbenkian, 1994, p. 187 
vingou: "Vivemos uma época de mudança acelerada. Numa única geração assistimos a tantas alterações que, eventualmente, os nossos filhos acharão que o estado de mudança é um ingrediente natural da vida. Talvez o meu filho venha a ficar intrigado perante os escritos de Parménides e surpreendido com o facto de ter sido possível que a filosofia ocidental tenha, durante tantos séculos, persistido na ideia que o mundo era um relógio." 31

No local de trabalho, a mudança provoca tensão e pode afectar a satisfação no trabalho, os índices de produtividade. ${ }^{32}$ Por outro lado, a mudança pode constituir o terreno fértil para a criatividade, ganhando, assim, um tom de desafio positivo. $^{33}$

Para Nigel Laurie, os filósofos constituem-se como os candidatos naturais ${ }^{34}$ a preencher o lugar dos responsáveis que permitam às $\mathrm{E} / \mathrm{O}$ a construção de novos conceitos ou modelos para os ajudar a pensar. ${ }^{35}$ Laurie aponta três razões para justificar a presença do filósofo no meio empresarial: o desenvolvimento de ferramentas utilizadas com sucesso ( $\mathrm{ex}^{\mathrm{o}}$ : o diálogo socrático); as mudanças rápidas que afectam as organizações; e, por último, a consciência crescente daquilo que a Filosofia pode oferecer. ${ }^{36}$

José Manuel Fonseca afirma no livro $O$ Paradoxo da Inovação Empresarial: "Sendo o conhecimento uma realidade não aditiva, e se a sua empresa possuir capacidade financeira para tal, considere a possibilidade de, em vez de mais um engenheiro de uma área em que já possui essa valência, contratar

\footnotetext{
${ }^{31}$ FONSECA José Manuel. - O Paradoxo da Inovação Empresarial, p. 84

${ }^{32}$ MORRIS Tom. - Op. Cit. - p. $150 .$.

${ }^{33}$ Ibidem.
}

34 A 22 de Outubro de 2007, o jornal Le Figaro publicava um artigo intitulado «De la philosophie à la banque, il n'y a parfois qu'un pas», onde relatava casos de empresas, neste caso da área bancária, que recrutavam pessoas licenciadas em Filosofia por considerarem que seriam portadoras de mais valias para o tecido organizacional: «Nous sommes convaincus que ces jeunes ont leur place chez nous. Ce sont des têtes bien faites. Nous avons recruté par exemple plusieurs philosophes qui sont parfaits dans les postes de middle office qui demandent une grande méthodologie, de l'organisation et de la curiosité», raconte Véronique Leenhardt». [On-Line] [29.01.2011] http://www.lefigaro.fr/emploi/2007/10/06/01010-20071006ARTFIG90891-

de_la_philosophie_a_la_banque_il_n_y_a_parfois_qu_un_pas.php

${ }^{35}$ LAURIE Nigel. - Art. Cit., p. 192. Sobre o pensar, leia-se o artigo de Jorge Larrosa BONDIA: «(...)E pensar não é somente "raciocinar" ou "calcular" ou "argumentar", como nos tem sido ensinado algumas vezes, mas é sobretudo dar sentido ao que somos e ao que nos acontece.». Notas sobre a experiência e o saber de experiência. - Revista Brasileira de Educação [On-Line] [15.09.2008]

http://www.anped.org.br/rbe/rbedigital/RBDE19/RBDE19_04_JORGE_LARROSA_BONDIA.pdf Mais uma vez, sublinhamos aqui um sentido amplo para o pensar, que não se reduz à intelectualidade ou à lógica, mas que é isso e algo mais. Cfr. a nota $\mathrm{n}^{\circ} 15$ de presente trabalho, relativa à inteligência emocional.

${ }^{36}$ Ibidem. 
antes um historiador, um filósofo ou um antropólogo. A forma de ver o mundo destas pessoas será diferente da vigente na empresa, que da reconstrução da realidade e dos processos da empresa que advirá das visões que possuem, poderão resultar ideias mais inovadoras sobre canais de distribuição ou sobre produtos do que aquilo que o seu ar céptico ao ler estas linhas permite perceber." 37 Para o professor José Manuel Fonseca, o filósofo (a par do historiador e do antropólogo) contribui com um olhar novo para a empresa, podendo ter um papel positivo e proactivo na inovação.

Para o editor de Philosophy of Management, Nigel Laurie, o consultor filosófico surge como o profissional com treino, capaz de oferecer um conjunto único de skills à organização. A que treino se refere Laurie? Exploração de conceitos e sua aplicação nos comportamentos de gestão, relação das ideias com a acção, avaliação dos diferentes pontos de vista, prática na construção de pensamentos experimentais, questões de lógica (teste da validade das proposições, identificando e ultrapassando contradições e generalizações abusivas), capacidade de ver aquilo que se encontra implícito no pensamento (as regras de que não se fala, bem como os valores dados como adquiridos) e que limitam o pensamento ou o tornam rígido. Os consultores filosóficos são facilitadores do diálogo e do questionamento, o que poderá ter consequências na eficácia organizacional. Nestes espaços de diálogo, a E/O e os seus colaboradores têm a oportunidade de trabalhar e desenvolver as suas competências (pessoais e interpessoais). Quais são as vantagens do diálogo? Segundo Laurie, o diálogo é vantajoso por permitir a quem o pratica a aprendizagem

- da gestão do comportamento verbal e não verbal,

- da procura dos dados de que precisa,

- da capacidade para reflectir perante a experiência e aprender pela criação de novas perspectivas,

- da escuta activa,

- do respeito pelos outros,

- do pensamento e dos conceitos (de forma a tornar claro o que é que aquele conceito significa no momento concreto),

- da capacidade de permitir o consenso e a gestão das diferenças de uma forma flexível.

\footnotetext{
${ }^{37}$ FONSECA José Manuel - O Paradoxo da Inovação Empresarial. - Oeiras: Metáfora, 1998, pp. 171-172.
} 
Godofredo J. Chilida Mejías defende a assessoria filosófica junto das empresas como uma forma de reflexão e de entendimento daquilo que acontece naquelas. ${ }^{38}$ Cita Martin T. Brown, autor do livro Corporate Integrity. Rethinking organizational Ethics and Leadership ${ }^{39}$ que compara as empresas actuais ao Titanic: "to be slowly moving in the wrong direction, but too big and powerful to change course."

\section{Filosofia prática ou filosofia aplicada?}

[What is philosophy?] I will define philosophical activity as an activity of the self determined by three conditions: identification, criticism and conceptualization. ${ }^{41}$

Philosophical Practice (em português, filosofia prática) surge pela primeira vez numa entrevista de Petra von Morstein, a 16 de Setembro de 1987 ao International Herald Tribune. ${ }^{42}$ No entanto, Lou Marinoff é o responsável pela difusão do uso da expressão Philosophical Practice. ${ }^{43}$

En coherencia con este sustantivo, el americano de origen canadiense, denomina practitioners a aquellos que se dedican profesionalmente a esta actividad. ${ }^{44}$

Marinoff classifica os practitioners da seguinte forma: client counselors (conselheiros filosóficos), group facilitators (facilitadores) e organizational consultants (consultores organizacionais). ${ }^{45}$ Os primeiros actuam no âmbito do

\footnotetext{
${ }^{38}$ La empresa como espacio aberto a la palabra. - Dominios de Aplicação Práctica de la Filosofia. [On-Line] [30.01.2011] http://issuu.com/jbbr/docs/dap

39 Nova Iorque: Cambridge University Press, 2005. [On Line] [29.01.2011] http://www.google.com/books?hl=pt-PT\&lr=\&id=-

HGPIZFnPC0C\&oi=fnd\&pg=PR9\&dq=corporate+integrity+rethinking+organizational+ethics+and+1 eadership\&ots=vyOXaVHHA4\&sig=bbNSBvkjaFXfBEkKMEUQbdVq60E $\#$ v=onepage \&q\&f=false ${ }^{40}$ Op. cit., p. 2.

41 Cfr. BRENIFIER Óscar. - Philosophy as Practice. - Philosophical Practice - [On-Line] [24.10.2010] http://issuu.com/jbbr/docs/philosophicalpractice/1

${ }^{42}$ Cfr. SCHUSTER Shlomit C. - What do I mean when I say "Philosophical Counselling" - [OnLine] 1996, [18-01-2011] http://sites.google.com/site/thephilosophicalcounselingweb/publicationlist/the-meaning-of-philosophical-counseling

Jose BARRIENTOS RASTROJO também assinala este momento na sua obra Introducción al Asesoramiento y la Orientación Filosófica. - Santa Cruz de Tenerife: Ediciones Idea, 2005, p. 21.

${ }^{43}$ MARINOFF Lou. - Philosophical Practice. - New York: Academic Press, 2002

${ }^{44}$ BARRIENTOS RASTROJO Jose. - Filosofía aplicada a la persona: propuesta para una rama de la filosofía contemporánea. - AA.VV.: Saber pensar para saber vivir. - Sevilha: Editorial Fénix, 2008, p. 13 .

${ }^{45}$ MARINOFF Lou. - Philosophical Practice. - New York: Academic Press, 2002, p. 139.
} 
gabinete particular, na consulta individual ${ }^{46}$ os segundos têm a sua acção dividida em no âmbito formal e informal. Por último, os consultores organizacionais que actuam na estrutura global da organização, podendo também actuar no âmbito do trabalho individual ou com o grupo.

"Levar a filosofia às pessoas, levar as pessoas a filosofar." - é desta forma que Tomás Magalhães Carneiro ${ }^{47}$ apresenta o seu trabalho no âmbito da filosofia prática. Schuster ${ }^{48}$ defende a ideia de que cada um de nós pode examinar a sua vida com o apoio de um filósofo. Trata-se de uma segunda revolução "socratiana". Sócrates ${ }^{49}$ antecipou a revolução coperniciana ao colocar no centro daquilo que realmente é fundamental para o ser humano o "conhece-te a ti mesmo", preterindo a origem social ou o sexo, a profissão como o "cartão de identificação" do ser humano. Nós somos aquilo que pensamos e agimos, mais do que aquilo que fazemos. Schuster também utiliza a expressão Filosofia Prática.

\footnotetext{
${ }^{46}$ Óscar Brenifier, Jose Barrientos Rastrojo, Jorge H. Dias são alguns dos profissionais que se dedicam à consulta individual.

Óscar Brenifier apresenta no seu site alguns casos de consulta: http://www.institut-de-pratiquesphilosophiques.com/

Quanto a Barrientos Rastrojo e Jorge H. Dias, podemos ter acesso a casos de consulta na obra BARRIENTOS RASTROJO Jose, DIAS Jorge H.. - Idea y Proyecto. - Madrid: Vision Libros, 2010 e Felicidad o Conocimiento? - Sevilha: Doss Ediciones, 2009.

47 Filosofía aplicada [On-Line] 2009

http://filosofiacritica.wordpress.com/author/filosofiacritica/

${ }^{48}$ SCHUSTER Shlomit C. - Everybody's Philosophical Counselling - [On-Line] 1997, [24-11-2010] http://sites.google.com/site/thephilosophicalcounselingweb/publication-list/the-meaning-ofphilosophical-counseling/everybodys-philosophical-counselling

${ }^{49}$ Era habitual para os atenienses o encontro com Sócrates e o diálogo que esse mesmo encontro proporcionava. Aliás, o estranho seria não encontrar o filósofo em conversa com quem, como ele, passeava pelas ruas de Atenas. Foi, aliás, isso que o condenou à morte. Sócrates nasceu em 468 a.C. e é considerado um marco indiscutível na história da filosofia ocidental. De tal maneira que os filósofos que o antecedem são denominados de pré-socráticos. Sócrates nada escreveu; o seu discípulo, Platão, é o responsável por tudo aquilo que conhecemos do marido de Xantipa. "When Socrates stated that the unexamined life was not worth living, it seems that he meant not just his own life or that of his family members, and not just the lives of the elite nor his fellow philosophers, but the lives of the timeless, universal crowd of people called humanity.» SCHUSTER Shlomit C. - Everybody's Philosophical Counselling $\quad-\quad$ [On-Line] [24-1-2010] http://sites.google.com/site/thephilosophicalcounselingweb/publication-list/the-meaning-ofphilosophical-counseling/everybodys-philosophical-counselling

Sobre Sócrates leia-se o artigo de P. A. T. Silva PEREIRA . - Logos Enciclopédia Luso Brasileira de Filosofia, Lisboa: Editorial Verbo, 1991, vol. 4, pp. 1216-1221.
} 
A filosofia não é uma tarefa mental; aspira de uma forma humilde e ao mesmo tempo ousada a um projecto de transformação integral e espiritual do homem. ${ }^{50}$

Em Portugal, surge em 2005 a Associação Portuguesa de Aconselhamento Ético e Filosófico (APAEF) e é precisamente essa expressão, aconselhamento filosófico, que vinga nos primeiros tempos de existência da Associação. Pioneira no nosso país, a Associação é a responsável pelas primeiras formações ${ }^{51}$ na área do aconselhamento filosófico. Se aplicarmos aqui a terminologia de Marinoff, teremos que indicar que a APAEF assumia o filósofo como um client counselor (em português, conselheiro filosófico). A expressão ganha força com a obra de Peter Raabe, intitulada precisamente Philosophical Counselling. Theory and Practice.

La comunidad internacional va convergiendo en una solución intermedia. El término Philosophical Counselors posee una leve preponderancia sobre Philosophical Practitioners para referirse al que trabaja en la orientación filosófica individual. Por su parte, Philosophical Practice se suele vincular con la profesión. Por último, counselee es el término para la persona que recurre a la consulta individual. ${ }^{.52}$

A utilização das expressões conselheiro, orientador ou mesmo assessor filosófico revela-se problemática por dar a entender que o papel do filósofo é o de "dar conselhos", "aconselhar" ou "dar pautas de actuação". Segundo Barrientos Rastrojo, o filósofo não deverá assumir o papel de condutor, dirigindo o outro

\footnotetext{
${ }^{50}$ SILVA Carlos H. do C. - Valor e essência da filosofia. - Revista Portuguesa de Filosofia. - Braga: Faculdade de Filosofia, 1982, tomo XXXVIII-II, p. 268.

${ }^{51}$ Em Janeiro de 2007 realizámos a nossa certificação no nível I, tendo realizado um trabalho de investigação na área da consultoria filosófica, denominado Das competências do Pensamento Criativo e o seu Contributo para o Aconselhamento e Consultoria Filosóficos. Na altura, tínhamos concluído a nossa certificação no método Six Thinking Hats®, de Edward de Bono e procurámos, nesse trabalho, explorar a questão do pensamento criativo no trabalho filosófico.

A este propósito, cfr. o artigo de Luís CENCILLO - Creatividad en la aplicacion de las filosofias a lo concreto. - Dominios de Aplicação Práctica de la Filosofia. - [On-Line] [29.01.2011] http://issuu.com/jbbr/docs/dap

Hoje em dia, esta Associação (APAEF) encontra-se aparentemente extinta. Foi, entretanto, criada uma outra Associação de seu nome Associação Portuguesa de Ética e Filosofia Prática (cfr. http://www.apefp.blogspot.com/ [20.01.2011]). Em Dezembro de 2010, a Associação promoveu o I curso de consultor / assessor filosófico, cujo formador foi o Professor Doutor Jose Barrientos Rastrojo (cfr. http://apefp.blogspot.com/2010/10/curso-de-consultor-filosofico.html [20.01.2011]).

${ }^{52}$ BARRIENTOS RASTROJO Jose. - Filosofía aplicada a la persona: propuesta para una rama de la filosofía contemporánea. - AA.VV.: Saber pensar para saber vivir. - Sevilha: Editorial Fénix, 2008, p. 13
} 
neste ou naquele sentido; deverá, sim permitir que o outro atenda a alternativas, abrindo-lhe o seu "campo de visão". ${ }^{53}$

Elliot Cohen é o responsável pela utilização da expressão Applied Philosophy (em português, Filosofia Aplicada), bem como pela edição da revista International Journal of Applied Philosophy, diz-nos Barrientos Rastrojo. ${ }^{54} \mathrm{~A}$ evolução da terminologia, em Portugal, é visível quando verificamos que em 2005 a APAEF organizou o I Encontro Português de Filosofia Prática, e dois anos depois realizou o IV Congresso Português de Filosofia Aplicada. ${ }^{55}$

Para Jose Barrientos Rastrojo, a Filosofia deve ser o eixo central da definição desta disciplina; daí defender a expressão Filosofia Aplicada em detrimento de Philosophical Practice ou Philosophical Counselling: em ambas a palavra "philosophical" surge como adjectivo e não como substantivo. ${ }^{56} \mathrm{E}$ o que é a Filosofia Aplicada?

Proceso de conceptualización y/o clarificación acerca de cuestiones relevantes (significativas y/o esenciales) para el consultante cuyo objetivo es la mejora de su acto de pensamiento y/o depuración de sus contenidos veritativos y cuyo resultado acostumbra a ser su bien-estar. Tanto en lo grupal como en lo individual, se plantea un trabajo mediante el cual el sujeto:

(1) Se hace cargo de su problema y lo articula conceptualmente.

(2) Reflexiona sobre las inmediaciones de esa articulación y sobre su tejido interno, ayudado por la historia del pensamiento.

(3) Asume las consecuencias de su modo de pensar.

(4) Busca un modo existencial adecuado a sus demandas internas y externas ${ }^{57}$

\footnotetext{
${ }^{53}$ BARRIENTOS RASTROJO Jose. - Introducción al Asesoramiento y la Orientación Filosófica. Santa Cruz de Tenerife: Ediciones Idea, 2005, p. 197

${ }^{54}$ BARRIENTOS RASTROJO Jose. - Filosofía aplicada a la persona: propuesta para una rama de la filosofía contemporánea. - AA.VV.: Saber pensar para saber vivir. - Sevilha: Editorial Fénix, 2008, p. 13.

${ }_{55}$ Tivemos oportunidade de participar como congressista no IV Congresso Português de Filosofia Aplicada, 16 a 18 de Novembro de 2007, Centro de Formação de Professores (Faro), com comunicação denominada $\mathrm{Da}(\mathrm{s})$ necessidade(s) filosófica(s) e do olhar filosófico sobre o mundo, no $(s)$ mundo $(s)$ de hoje.

${ }^{56}$ «Nosotros consideramos que la Filosofía debe permanecer, también en su denominación, como eje central. Achenbach, uno de los fundadores de la disciplina, en sus inicios como filósofo aplicado, se consideraba un filósofo dedicado aplicar la filosofía en un universo específico; nunca pensó que fuese, ante todo, un orientador o un psicólogo que usaba herramientas filosóficas. Somos ante todo filósofos dedicados a un ámbito específico de intervención.» BARRIENTOS RASTROJO Jose. Filosofía aplicada a la persona: propuesta para una rama de la filosofía contemporánea. - AA.VV.: Saber pensar para saber vivir. - Sevilha: Editorial Fénix, 2008. Págs. 11-31. Esta posição já tinha sido defendida por BARRIENTOS (Cfr. Introducción al Asesoramiento y la Orientación Filosófica. - Santa Cruz de Tenerife: Ediciones Idea, 2005, p. 197).

57 BARRIENTOS RASTROJO Jose.- Corrientes actuales europeas del pensamiento y filosofía aplicada. - Revista Tales, 2008, $\mathrm{n}^{\circ}$ 1, Madrid: Universidad Complutense de Madrid, pp. 135-150.
} 
Na perspectiva de Barrientos Rastrojo, os conteúdos da Filosofia Prática não esgotam o conteúdo profissional da Filosofia Aplicada. ${ }^{58} \mathrm{O}$ filósofo considera que, no âmbito das consultas ou dos trabalhos com grupos, é comum surgirem questões de índole ética, e não só. Outras questões incomodam as pessoas e podem ter um cariz epistemológico, estético ou mesmo metafísico.

The essential difference between applied philosophy and philosophical practice is that in the former, a philosopher applies philosophical theories to problematic situations, while in the alter the counselee does the philosophizing - with help from the philosopher - about the problematic circumstance or question." ${ }^{, 59}$

Do aconselhamento filosófico à Filosofia Aplicada, passando pela filosofia prática: eis o caminho percorrido pelos nomes de referência das NPF (cfr. ilustração 1).

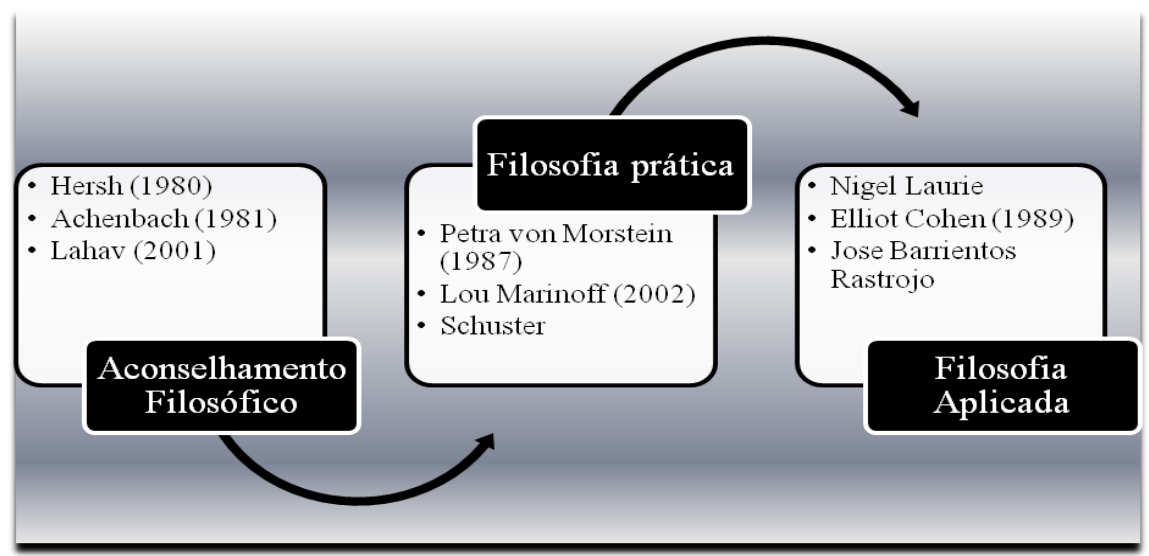

ILUSTRAÇÃO 1 - DO ACONSELHAMENTO FILOSÓFICO À FILOSOFIA APLICADA

\footnotetext{
${ }^{58}$ BARRIENTOS RASTROJO Jose. - Filosofía aplicada a la persona: propuesta para una rama de la filosofía contemporánea. - AA.VV.: Saber pensar para saber vivir. - Sevilha: Editorial Fénix, 200, p. 18

${ }^{59}$ SCHUSTER S. C., Philosophy Practice, an alternative to counseling and psychotherapy. Cit. por BARRIENTOS RASTROJO Jose - Vectores Zambranianos para una Teoría de la Filosofía $\begin{array}{llllll}\text { Aplicada } & a & \text { la } & \text { Personar } & - & \text { [On-Line] [08.12.2010] }\end{array}$ http://fondosdigitales.us.es/tesis/tesis/1010/vectores-zambranianos-para-una-teoria-de-la-filosofiaaplicada-la-persona/
} 


\section{Filosofia nas empresas e organizações: o consultor filosófico}

El orientador filosófico debe provocar la necesidad de que emerja en el plano empresarial el mundo vital, lo ético y lo solidario. Este es un trecho largo y difícil y nunca puede ser confundido con una labor del representante de los trabajadores o del sindicato, nada más alejado. ${ }^{60}$

La idea de incluir a filósofos en organizaciones forma parte de una de las líneas de la Filosofía Aplicada (...). ${ }^{61}$

$\mathrm{O}$ que pode efectivamente fazer um filósofo nas $\mathrm{E} / \mathrm{O}$ ? $\mathrm{Na}$ perspectiva da Associação Americana de Filósofos Práticos ${ }^{62}$ o trabalho do filósofo apresenta três áreas de actuação possíveis: o trabalho de conselheiro/orientador filosófico, o trabalho de facilitador com grupos, o trabalho a desempenhar nas organizações. ${ }^{63}$

Lou Marinoff considera que os filósofos têm cada vez mais diferentes papéis para assumir nas organizações, de forma a ajudar estas a atingir os seus objectivos. "When people are assembled under the aegis of na organization, for the purpose of earning livelihoods, pursuing careers or attaining similar goals, they experience problems and difficulties both recognizable in the broader human estate yet manifest in identifiably unique days." ${ }^{64}$ Cada organização apresenta uma missão, a sua "razão de ser". Quando se conhece a missão da empresa, podem estabelecer-se estratégias no sentido de a fazer cumprir.

A este propósito, Tom Morris alerta-nos para o papel e a importância da verdade: “(...) a verdade liberta. Liberta as pessoas para serem e fazerem o seu melhor. Se souberem onde estão e o que se passa, podem perceber como fazer o que tem que ser feito. Os seres humanos podem ser surpreendentemente criativos quando lhes são facultadas as matérias-primas e a devida oportunidade." ${ }^{\prime 65}$

\footnotetext{
${ }^{60}$ BARRERA Francisco. - Su empresa puede estar necesitando un filósofo. - in La filosofia a las puertas del tercer milénio. - Sevilha: Fénix Editora,2005, pp. 163-170

61 BARRIENTOS RASTROJO Jose. - Vectores Zambranianos para una Teoría de la Filosofía $\begin{array}{llllll}\text { Aplicada } & a & l a & \text { Personar } & - & \text { [On-Line] [08.12.2010] }\end{array}$ http://fondosdigitales.us.es/tesis/tesis/1010/vectores-zambranianos-para-una-teoria-de-la-filosofiaaplicada-la-persona/

${ }^{62}$ Consulte-se o sítio da Associação em http://www.appa.edu/

${ }^{63}$ ARNAIZ Gabriel. - Introducción a la Practica Filosófica en las Organizaciones. - AA.VV. - Saber pensar para saber vivir. - Sevilha: Fénix Editora, 2008, p.35.

${ }^{64}$ MARINOFF Lou. - Philosophical Practice. - p. 157.

${ }^{65}$ MORRIS Tom. - Se Aristóteles fosse Administrador da General Motors. - Lisboa: Publicações Dom Quixote, 2009, p. 68.
} 
Para Tim Lebon, o filósofo é portador de uma toolbox única que lhe permite um trabalho diferenciador no seio das $\mathrm{E} / \mathrm{O}$, bem como no counselling one-toone $e^{66}$. Essa toolbox compreende cinco métodos ${ }^{67}$ :

1. Pensamento crítico; ${ }^{68}$

2. Análise conceptual;

3. Fenomenologia;

4. Experiências de pensamento;

5. Pensamento criativo.

"Thinking straight is their business. ${ }^{" 69}$ Recordemos Nigel Laurie: para o autor de Philosophy Goes to Work, o contributo da Filosofia no trabalho tem uma tripla acção: pode ser aplicada ao trabalho, pode ser posta em prática no trabalho e pode ser direccionada para o mundo do trabalho como uma actividade da gestão. Uma vez aplicada ao trabalho, a Filosofia pode estar presente nos assuntos relacionados com a ética e procedimentos internos. No que respeita à Filosofia que se coloca em prática no trabalho, esta acontece quando os filósofos operam enquanto facilitadores e professores do pensamento. Nesse momento, os colaboradores com quem o filósofo está a trabalhar encontram-se em processo de prática da Filosofia.

Para Dorine Bauduin e Ida Jongsma ${ }^{70}$, os métodos filosóficos podem contribuir para a mudança das atitudes das pessoas face ao seu trabalho. As autoras apontam para a necessidade de philosophical skills nos cargos mais altos no que respeita à comunicação interpessoal (eficiência de reuniões, trabalhos em grupo, desenvolvimentos de projectos); alertando para o aumento de questões éticas no seio da sociedade contemporânea, sem esquecer a necessidade que as $\mathrm{E} / \mathrm{O}$ têm em justificar as suas políticas de forma pública. $\mathrm{O}$ que podem os consultores filosóficos oferecer às $\mathrm{E} / \mathrm{O}$ ? Segundo as autoras, existem cinco aspectos que justificam a presença do consultor filosófico numa empresa:

\footnotetext{
${ }^{66}$ Tim LeBon apresenta-nos uma perspectiva da filosofia prática, aplicada ao nível da terapia.

${ }^{67}$ LEBON Tim. - Wise Therapy - Londres: Sage Publications, 2007, p. 4.

${ }^{68}$ Em inglês, critical thinking. «(...)un modo de maximizar la capacidad de argumentar, de desvelar errores de pensamiento y analizar el peso de unas razones sobre otras.» BARRIENTOS RASTROJO Jose. - Philosophical Counselling as Critical Thinking - I Encontro Português de Filosofia Prática, 29 de Agosto de 2005.

No Anexo A apresentamos o esquema/quadro recorrente apresentado por Jose Barrientos Rastrojo, na sua dissertação de doutoramento.

O pensamento crítico é, também, uma «bandeira» da filosofia para crianças. Cfr. Matthew LIPMAN. - Op. Cit., p. 54.

${ }^{69}$ LAURIE Nigel. - Philosophy goes to work - in CURNOW Trevor (ed.) Thinking Through Dialogue. - Practical Philosophy Press, 2001, p. 192

${ }^{70}$ BAUDUIN Dorine, JONGSMA Ida. - For better or for worse? Philosophy in Business - Thinking Through Dialogue. - Practical Philosophy Press, 2001, p. 204
} 
1. Apresentam as skills que permitem tornar explícitas as perspectivas ocultas e modos de pensar, sublinhando regras e valores, de forma a salientar o óbvio;

2. São capazes de reflectir nos conceitos e na forma como os conceitos influenciam a nossa acção. O filósofo consegue ilustrar a forma como o pensamento e a acção estão relacionados e desmascaram possíveis inconsistências. $^{71}$

3. Facilitam uma análise comum dos conceitos, através de instrumentos metodológicos, como o diálogo ou as técnicas dialécticas, de forma a "desmontar" a argumentação.

4. São estimulantes do pensamento independente; incentivam a que cada um de nós pense por si e seja capaz de pensar pelo outro.

5. O seu conhecimento amplo de teorias e perspectivas filosóficas pode ser aplicado na prática filosófica, no seio empresarial.

Francisco Barrera relata-nos o caso de três empresas sujeitas à presença do filósofo. Num desses casos a Filosofia assumia o papel de ensinar os colaboradores a pensar, no sentido de promover a mudança no seio da organização. O Orientador Filosófico define dois tipos de colaboradores: os nocionais e as pessoas pensantes. ${ }^{72}$ As primeiras constituem-se como "bibliotecas itinerantes", onde é possível consultar os procedimentos administrativos. Todavia, não sabem decidir nem usar a informação de que são detentores para decidir. As segundas são a chave mestra capaz de abrir qualquer porta. Numa era em que se defende a bandeira das learning organizations e mesmo uma perspectiva espiritual ${ }^{73}$ e holística ${ }^{74}$ no local de trabalho, a presença de um filósofo surge-nos como uma possibilidade de imprimir sentido ao dia a dia dos colaboradores.

\footnotetext{
${ }^{71}$ Nas palavras das autoras: «(...)the philosopher works towards practical wisdom by taking everyday practice and the experiences of participants as a starting point for analysis, and by clarifying the preconceptions that form the basis of everyday practice.»-Art. cit., p. 205.

Tal perspectiva volta a aproximar-nos da figura de Sócrates, bem como do texto de Leonard NELSON ( El método socrático. - Cádiz: Huqualya,, 2008). Cfr. nota de rodapé $\mathrm{n}^{\circ} 14$.

${ }^{72}$ BARRERA Francisco. - Art. Cit., p. 167.

${ }^{73}$ QUATRO Scott A. - New Age or Age Old: Classical Management Theory and Traditional Organized Religion as Underpinnings of the Contemporary Organizational Spirituality Movement. Human Resource Development Review [On-Line] 2004, vol 3, $\mathrm{n}^{\circ} 3$, pp. 228-249 [27.04.2009] http://hrd.sagepub.com/cgi/content/abstract/3/3/228

${ }^{74}$ LEE Monica. - Art. Cit., pp. 97-110
} 


\section{Aproximações ao perfil do consultor filosófico}

Las modificaciones vividas en sociedad crean en la persona un conjunto de necesidades (muchas de ellas filosóficas) y un deseo de tranquilidad. Para mí, la orientación es una respuesta de algunos profesionales a las necesidades (filosóficas) conducentes a un sentimiento de equilibrio y realización. ${ }^{75}$

Justificamos a existência do consultor filosófico junto dos recursos humanos, nas $\mathrm{E} / \mathrm{O}$, por considerarmos que as pessoas apresentam necessidades intrinsecamente filosóficas.

Nos últimos dois anos, onde quer que vá nos Estados Unidos, tenho testemunhado uma coisa que nunca tinha previsto. No fosso de dificuldades financeiras ou na sequência de sucessos tremendos, em lugares onde nunca se imaginaria, em bons e maus momentos, pessoas de todos os tipos começam, inesperadamente, a fazer uma coisa que do meu ponto de vista de filósofo está profundamente certa.

Depois de esgotarem todas as possibilidades, pessoas normais em todo o lado começam de repente a tornar-se filósofos. Pessoas de todos os tipos estão a envolver-se naquela espécie de compromisso de atenção e intelecto (...) Em todas as regiões do país, vi pessoas começarem a pensar de uma forma nova acerca do seu trabalho e das suas vidas. Começam a filosofar, a reflectir profundamente sobre algumas das suas suposições mais básicas e a questionar como querem viver realmente. Estão a procurar confrontar as grandes questões e a perguntar como é que essas questões se aplicam às suas vidas neste momento."

Lou Marinoff define como componentes da artistry $^{77}$ do consultor filosófico que actua nas E/O "charisma, confidence, credibility, charm, energy, flair, perceptiveness, reactivity, spontaneity, style, technical mastery, improvisational skill, showmanship, and the right balance of gravity and levity.

\section{Necessidades filosóficas}

Don Petersen, antigo presidente da Ford Motor Company, conta uma história interessante. Uma vez, quando estava a visitar uma metalúrgica em Buffalo, Nova

\footnotetext{
${ }^{75}$ DIAS Jorge Humberto. - La felicidad como objectivo de la filosofia aplicada. - Filosofia Aplicada a personas y grupos. - Sevilha: Doss Ediciones, 2008, p. 55

${ }^{76}$ MORRIS Tom. - Op. Cit., - p. 26

${ }_{77}^{77}$ Algumas traduções possíveis para esta palavra: mestria ou habilidades.

${ }^{78}$ «Some of these qualities (e.g. technical mastery, perceptiveness, style) can be developed by direct practice; others (e.g. confidence, spontaneity, energy) can be enhanced by indirect practice; others still (e.g. allure, intensity, humor) appear to be gifts of nature, which can be diminished by adverse circumstance but cannot be greatly augmented by exercise.» Cf. MARINOFF Lou. - Philosophical Practice. - ., p. 169
} 
Iorque, um homem enorme aproximou-se dele e disse: "Sabe, quero dizer-lhe uma coisa. Eu detestava vir trabalhar para aqui. No entanto, ultimamente perguntaramme o que penso e isso faz-me sentir que sou alguém. Nunca pensei que a empresa me visse como um ser humano. Agora, gosto de vir trabalhar." 79

As pessoas, nas E/O, apresentam necessidades filosóficas? Consideramos que sim e que estas necessidades não têm só manifestação nas $E / O$, mas sim onde quer que existam pessoas. Mas foquemo-nos nos recursos humanos das empresas e organizações.

Em $2007^{80}$ tivemos oportunidade de apresentar um primeiro esboço do que serão as necessidades filosóficas, tendo estabelecido quatro grandes núcleos, que passamos a enunciar: necessidade de inquisição, necessidade de diálogo versus escuta activa, necessidade de perspectivas diferentes sobre a mesmidade e a necessidade de compreensão das convicções.

\section{Necessidade de inquisição/questionamento}

Why to deny the questioning as a form of communication? However, Socratic dialogue is the communication between two beings: once you start a dialogue, you begin to communicate. Questions simply seek knowledge, understanding of words and links between them. Questions force us to find our knowledge somewhere in our mind, in a collective thinking ${ }^{81}$

Óscar Brenifier defende o questionamento como uma forma de comunicação e a questão como o primeiro passo da comunicação entre dois seres. No seu trabalho de questionamento (com crianças e adultos), Brenifier considera a pergunta como uma abertura para o mundo e o ser, atribuindo-lhe, até, um valor estético, provocador. A pergunta produz um conceito ou uma ideia, na forma de uma resposta - ou não. Diz-nos o responsável pelo Institut de Pratiques Philosophiques que as perguntas boas e profundas não podem ser respondidas. Diz mesmo que não devem ser respondidas, mas sim problematizadas. O questionamento é defendido como uma ferramenta que nos permite explorar os limites do conhecimento e da compreensão. ${ }^{82}$

\footnotetext{
79 MORRIS Tom. - Op. Cit. - , p. 51.

${ }^{80} \mathrm{Cfr}$. notas de rodapé 50 e 54 .

81 BRENIFIER Óscar. - Philosophy and Communication - [On-Line] 29.09.2010 [30.01.2011] http://www.institut-de-pratiques-philosophiques.com/?p=152

${ }^{82}$ BRENIFIER Óscar - How to avoid children's questions. - [On Line] 29.09.2010 [30.01.2011] http://www.brenifier.com/english/\#

Óscar Brenifier é autor de inúmeros livros de Filosofia para Crianças e realiza seminários de questionamento com adultos, um pouco por todo o mundo. Certo dia, num seminário, perguntámos
} 
The idea is that a question has value in itself, it is an opening upon the world and being, it has necessarily produced a concept or an idea, in a negative form which is no less valuable than its mirror image: the answer. A question has an esthetic value, its form is mind provoking, similar in this aspect to a painting or sculpture which the spectator contemplates without back thoughts and emergency preoccupations about the utility, the truth or the resolution of the problem offered to his senses and reason. This perspective does not prohibit any tentative of answering, but the answer is deemphasized, de-idolized, loosing therefore its status as the final and ultimate step of mind activity and process. Good and profound questions cannot be answered, and should not be answered. They can only be problematized, which for us means that we can initially analyze their content and appreciate them for what they bring, and in a second step start producing ideas as hints that can shed a light on different paths it can embark us upon. Questioning is a mind experiment, a tool allowing to explore the limits of knowledge and understanding

Lou Marinoff sublinha: "Os seres humanos querem e precisam de perceber o sentido das coisas que acontecem - ou que não acontecem -, tanto a curto como a longo prazo." 83

\section{Necessidade de diálogo vs escuta activa}

O diálogo e a escuta activa constituem-se como uma necessidade filosófica pelo facto de permitirem o acesso aos conceitos que estão subjacentes àquilo que se diz. Temos acesso ao ser através do pensar, expresso pela linguagem. Para que esse acesso se efective, é necessário dialogar e escutar. Para Martin Heidegger, a linguagem é o acontecimento originário. $\mathrm{O}$ autor de Sein und Zeit atribui à linguagem uma função essencial: “(...) a linguagem é o que primeiro traz ao aberto o ente enquanto ente." 84

Nigel Laurie fala-nos do papel do consultor filosófico enquanto moderador ou facilitador dos diálogos socrático. ${ }^{85}$ De uma forma estruturada, estes diálogos

ao Professor se não poderia vir a Portugal ministrar um curso sobre a metodologia da filosofia para crianças. A sua resposta foi: «Para quê? É a mesma coisa. Tudo gira em torno do questionamento.» Por este motivo, apresentamos este excerto de um artigo sobre as perguntas das crianças para ilustrar a necessidade de inquisição/questionamento das pessoas, pelo forma como é descrita e encarara a pergunta. Esta constitui o movimento primeiro para a comunicação, entre as pessoas.

${ }^{83}$ MARINOFF Lou - As Grandes Questões da Vida - , Lisboa: Editorial Presença, 2005, $1^{\text {a }}$ edição; p. 17

${ }_{85}^{84}$ HEIDEGGER Martin. - A Origem da Obra de Arte. - p. 59.

${ }^{85}$ Cfr. LAURIE Nigel - Philosophie goes to Work. - Thinking Through Dialogue. - Practical Philosophy Press, 2001, p. 193.

Cfr. a introdução do presente trabalho, em que referimos o texto de NELSON, Leonard. - El método 
permitem que os colaboradores discutam questões relacionadas com a liderança, a cultura organizacional, as forças e as fraquezas da $\mathrm{E} / \mathrm{O}$, a visão do negócio, a missão; desta forma, o colaborador pode, a partir de uma questão colocada pelo próprio ou por outro, questionar e procurar, em grupo, respostas, caminhos, hipóteses que os conduzam (e à $\mathrm{E} / \mathrm{O}$ ) num caminho de maior eficácia.

Para Dorine Bauduin e Ida Jongsma, o diálogo socrático ${ }^{86}$ revela-se como um método de inquisição rigorosa aos nossos pensamentos, conceitos e valores que consideramos como sendo nossos, como sendo verdadeiros. Este método revela-se uma forma de investigação ${ }^{87}$, em comunidade, ${ }^{88}$ acerca das nossas assumpções ao proferir determinada afirmação.

O papel do diálogo é indicado como uma forma de obtenção de flexibilidade estrutural e liderança nas empresas: "permita que os seus colaboradores dialoguem abertamente, facilite a circulação de informação, promova a circulação de artigos e revistas sobre técnica e tecnologia (...)"89 José Manuel Fonseca e Tom Morris concordam, assim, que o conhecimento deve ser partilhado. Morris diz que o conhecimento partilhado se expande: "E, à medida que o conhecimento se expande, o poder expande-se." ${ }^{.90}$ A abordagem de Morris face à vida empresarial centra-se no conceito de partilha de conhecimento com todos os colaboradores; isto implica adoptar a "gestão de livro aberto"; o

\footnotetext{
socrático.

${ }^{86}$ Sócrates é tomado como referência pelo coaching, nomeadamente a sua expressão «dar à luz as ideias»: «O coaching é essencialmente "a arte de fazer dar à luz", ou seja, um processo marcadamente maiêutico. O executivo é o parturiente e denomina-se "cliente" do processo de coaching. (...) O coach é o parteiro (...).» REGO Arménio, PINA E CUNHA Miguel. OLIVEIRA Carlos Miguel, MARCELINO Ana Regina. - Coaching para executivos - Lisboa: Escolar Editora, 2004, p. 24.

Gostaríamos de ter tido oportunidade de explorar o coaching, numa perspectiva comparativa face à consultoria filosófica nas E/O. Numa primeira abordagem, consideramos que o coaching vai beber muito do seu método à filosofia e, consequentemente, à filosofia aplicada às E/O.

${ }^{87}$ BAUDUIN Dorine, JONGSMA Ida. - For better or for worse? Philosophy in Business - Thinking Through Dialogue. - Practical Philosophy Press, 2001, p. 206.

${ }^{88}$ Mais uma vez, salientamos aqui a metodologia lipmaniana no que respeita à prática da filosofia para crianças. O Professor Lipman defendia, precisamente, o conceito de comunidade de investigação. «O progresso da investigação é progressivo no que respeita à quantidade das crenças estabelecidas no progresso de investigação. "É preciso cultivar um processo de investigação sem limites nem obstáculos na fixação de crenças cada vez mais sólidas." (1999a, 104) Nesta perspectiva o pioneiro de FpC [Filosofia para Crianças] vê a comunidade como o ponto de partida e de chegada do diálogo da aventura de cada investigação na filosofia. Sendo que para Peirce a investigação "é que almeja descobrir suas próprias franquezas e corrigir o que é falho em seus próprios procedimentos." (2001, 179).» LIMA Denise de. - Filosofia para crianças : uma abordagem crítica dentro da filosofia da educação - dissertação de mestrado em Educação, Universidade do Minho, 2004 [29.01.2011]. http://repositorium.sdum.uminho.pt/handle/1822/4925

${ }^{89}$ FONSECA José Manuel. - p. 172.

${ }^{90}$ MORRIS Tom. - p. 66.
} 
que na prática conduz a que a empresa apresente aos seus colaboradores toda a informação sobre aquela. Defende-se o princípio de que as pessoas bem informadas apresentam uma prestação de excelência, a longo prazo.

\section{Necessidade de perspectivas diferentes sobre a mesmidade}

A atitude de olhar para a mesma realidade, ainda que de modo diferente. De acordo com Barrientos Rastrojo, ${ }^{91}$ o filósofo permite o ampliar do campo de visão da pessoa a quem a ele recorre. A Filosofia Aplicada é, também, uma forma de autoconhecimento. Maria Zambrano defendeu isso mesmo. ${ }^{92}$ Marinoff sublinha: "Mas as pessoas sentiam a falta do tipo de conselhos que os filósofos podem dar e das diversas perspectivas que podem oferecer e, por isso, nas últimas décadas, a prática filosófica teve um ressurgimento surpreendente."93

Salientamos aqui o papel do pensamento criativo, indicado por Lipman como uma das áreas a ser desenvolvida em Filosofia para Crianças. As crianças dizem, com frequência, que o modo como vêem as coisas é o único possível, sem considerar alternativas. O papel da filosofia (para crianças) é o de “(...) libertálas de uma mentalidade estreita - sugerindo que pode haver outras possibilidades a explorar e ajudando-as a identificarem e examinarem essas possibilidades alternativas." $" 94$

Já Edward de Bono, um "guru" da criatividade junto das empresas e organizações, defende: "Cada vez mais a criatividade começa a ser considerada um ingrediente essencial para a mudança e o progresso. Começa a ser colocada acima do conhecimento e da técnica, já que estes dois últimos são cada vez mais acessíveis" $" 95$

Há quem aconselhe aos empresários e gestores a orgqanização de concursos de ideias absurdas, valorizando a recompensa da criatividade (para além da produtividade). José Manuel Fonseca diz-nos ainda que a empresa pode (e deve) promover o encontro dos seus colaboradores com consultores e investigadores

\footnotetext{
${ }^{91}$ Cfr. nota de rodapé $\mathrm{n}^{\circ} 57$ do presente trabalho.

${ }^{92}$ ZAMBRANO, Maria. - Hacía un saber sobre el alma - Alianza: Madrid, 2004.

93 MARINOFF Lou - As Grandes Questões da Vida - , Lisboa: Editorial Presença, 2005, $1^{\text {a }}$ edição; p. 17

${ }_{94}$ LIPMAN Matthew, OSCANYAN Frederick D., SHARP Ann Margaret - Filosofia na sala de aula. - São Paulo: Nova Alexandria, p. 170

${ }^{95}$ BONO Edward de - O Pensamento Lateral - Lisboa: Pergaminho, 2005, $1^{\text {a }}$ edição, p. 11. Diz-nos ainda o autor: «Um salto em frente criativo pode empurrar o nosso pensamento para a frente. Partimos de um ponto mais adiantado. Sem o pensamento criativo, partimos de trás e temos de fazer um esforço para empurrar a ideia para a frente a partir daquilo que já sabemos. A atitude criativa implica que haja vontade de avançar e explorar novas possibilidades.» Edward de BONO - Ensine os Seus Filhos a Pensar - Cascais: Editora Pergaminho, 2003, 1a edição, p. 231.
} 
que defendam perspectivas divergentes. ${ }^{96}$ "As pessoas gostam de novidade. Sentem curiosidade. E, paradoxalmente, gostam de mudança, de experimentar coisas diferentes." 97

Arménio Rego e Miguel Pina e Cunha apresentam-nos mais exemplos inovadores que abrem portas à criatividade, aliadas ao riso e à predisposição para a mudança.98 Paulo Morgado publicou recentemente um livro intitulado O Riso em Bergson - Mecanismo do Cómico99, onde explora o cómico e a gestão das empresas. "Percebendo os mecanismos do cómico percebemos os mecanismos da inteligência e esta é, entre outras coisas, a capacidade que temos para resolver os problemas. Se falta humor dentro das nossas empresas? Para já, falta claramente aos cargos de alta direção mais capacidade para fazerem coisas sem ser exercer os seus cargos, ostentar o seu poder e jogar golfe. Falta um ambiente cultural que tinham obrigação de fazer, saindo dos seus produtos. Há ainda hoje muito provincianismo... Um exercício muito interessante para essas pessoas é rirem-se delas próprias." 100

\section{Necessidade de compreensão das convicções}

instead of rushing to other ideas, or rather other intuitions, before piling more words, why not to take time to determine and evaluate connections between concepts and ideas, in order to become aware of the nature and the range of our speech. There again, impatience is reigning : this work is plodding, it is obviously less glorious and more frustrating, and yet, is it not more consistent?" ${ }^{101}$

\footnotetext{
${ }^{96}$ O paradoxo da inovação empresarial. - p. 171.

${ }^{97}$ Idem. - p. 83

${ }^{98}$ Porque falham as mudanças - ou porque as pessoas resistem à mudança. - A essência da liderança . - Lisboa: RH Editora, 2004, pp. 77 - 131

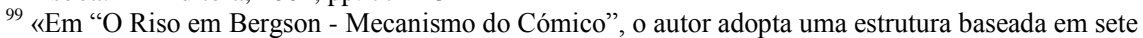
pilares (Analogia, Transposição, Ambiguidade, Absurdo, Contraste, Ressalto e Caricatura) para explicar, com grande detalhe, como é que estes se podem conjugar para despoletar o riso (ou o pensamento...). Os exemplos de utilização destes mecanismos são abundantes ao longo das páginas desta obra, não faltando hilariantes piadas e anedotas que ilustram, de forma apropriada e criativa, os diversos passos do pensamento do autor.» [On-Line] [22. 08.2011] http://www.rhonline.pt/noticias/default.asp?IDN=864\&op=2\&ID=12\&IDP=5\&P=5

Ainda sobre a Filosofia e o Cómico, recomendamos CALERO Pedro González - A Filosofia com humor. - Lisboa: Planeta, 2009, $1^{\text {a }}$ edição.

${ }^{100}$ Cfr. CARREIRA Duarte Albuquerque - Art. Cit., $\mathrm{n}^{\circ}$ 102, Abril de 2011

101 BRENIFIER Óscar - Knowing what we are saying. - [On-Line] 29.09.2010 [30.01.2011] http://www.institut-de-pratiques-philosophiques.com/?p=154

Para o aprofundamento desta questão, leia-se ainda ORDÓÑEZ GARCÍA, J. - MACERA GARFIA, F. - BARRIENTOS RASTROJO, J. - Creencia, teoría, revelación y coincidencia consigo mismo - La filosofía a las puertas del tercer milenio - Sevilha: Féniz Editora, 2005, pp.. 229-237.

Falta-nos, de momento, apresentar aquí a visão de Charles Peirce, um pragmatisma que se encontra
} 
Parar para pensar - é uma das frases mais repetidas nos seminários de questionamento ministrados pelo Professor Óscar Brenifier. Porquê ? Precisamente porque nós estamos habituados a pensar, partilhar ideias, defender posições, mas nem sempre sabemos o porquê, nem mesmo as consequências do meu pensar e como pode o agir encontrar-se em harmonia com o pensar.

Brenifier salienta a necessidade de compreensão no que respeita à questão do pensamento crítico: “(...) notre thèse soutient l'idée que l'essentiel de la citoyenneté repose sur l'esprit critique. (...) Critiquer implique d'abord de connaître, en outre de compreendre, cars sans comprendre, comment passer ao crible, comment critiquer ?"102

Mais uma vez, recorremos a Marinoff: "Compreender de que forma as convicções, e as convicções sobre convicções, podem melhorar - ou piorar - a vida dos seres humanos também é uma tarefa filosófica." 103 Aquilo que nos acontece depende da nossa interpretação da realidade - a causa é pessoal, depende da interpretação de cada um. Assim, se eu controlar a interpretação, serei capaz de interpretar o seu efeito. ${ }^{104}$

\section{Modelo de análise}

Tendo em conta as noções de Filosofia Aplicada abordadas na revisão de literatura, procuraremos aplicá-las ao contexto dos recursos humanos ${ }^{105}$ inquirindo sobre a existência de necessidades filosóficas no seio das E/O.

Consideramos que o consultor filosófico pode contribuir com um olhar distinto nas E/O. A nossa investigação cumpre-se testando a hipótese de que as pessoas, nas E/O, apresentam necessidades de índole filosófica. De forma a definir essas necessidades, construímos um questionário e uma entrevista, ${ }^{106}$ que

na origen dos programas de Filosofia para Crianças, apresentados pelo já aquí referido Professor Lipman: «(...) as ideias (que em si mesmas são apenas parte da nossa experiencia) tornam-se verdadeiras precisamente e na medida em que nos ajudam a establecer uma relação satisfatória com as outras partes da nossa experiencia.» GOMES F. Soares - Pragmatismo - Logos Enciclopédia Luso Brasileira de Filosofia, Lisboa: Editorial Verbo, 1991, vol. 4, p. 396.

${ }_{102}$ BRENIFIER Óscar. - Enseigner par le débat. - CRDP de Bretagne: França, 2002, p. 25.

${ }^{103}$ MARINOFF Lou - As Grandes Questões da Vida - , Lisboa: Editorial Presença, 2005, $1^{\text {a }}$ edição; p. 27

104 Jose BARRIENTOS - Introducción al Asesoramiento y la Orientación Filosófica. - Santa Cruz de Tenerife: Ediciones Idea, 2005, p. 94).

105 Deverá entender-se recursos humanos como as pessoas, os colaboradores das E/O, independentemente do cargo ou função que ocupem.

${ }^{106}$ Cfr. capítulo IV do presente trabalho. 
nos vão permitir compreender que necessidades são essas, bem como a sua identificação junto de uma dada população.

Através deste trabalho procuramos dar razões e justificar o papel do consultório filosófico no meio empresarial, bem como contribuir para a própria filosofia aplicada, com um trabalho académico que pretende dar corpo a uma visão de parceria entre a Filosofia e os Recursos Humanos.

Pretendemos contribuir para a construção do perfil do consultor filosófico, dando continuidade a um primeiro esboço realizado no passado, bem como desenvolver ferramentas para a filosofia aplicada.

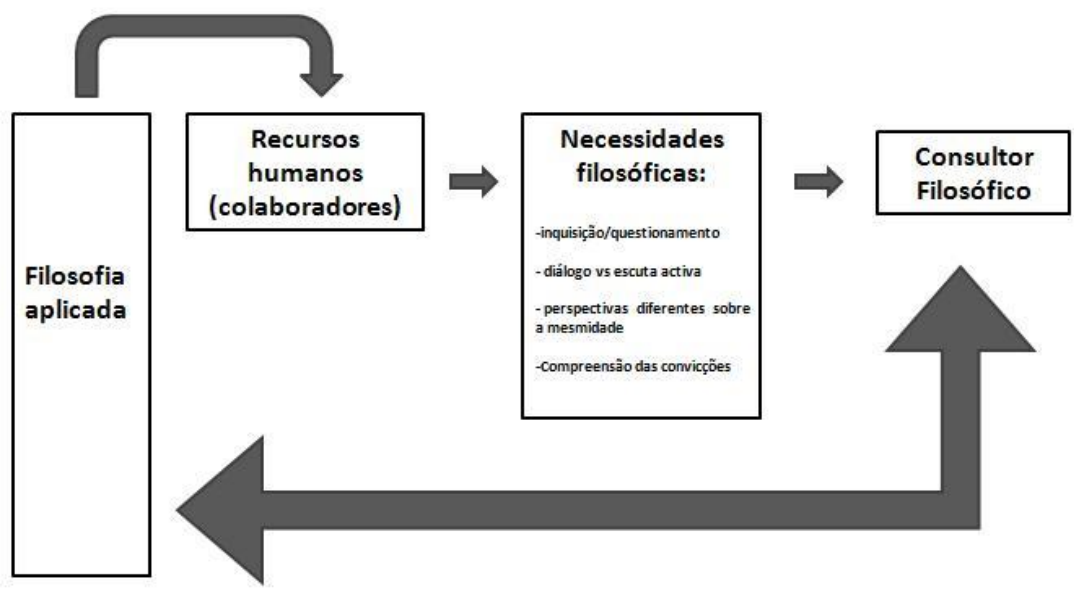

ILUSTRAÇÃO 2 - MODELO DE ANÁLISE

\section{Metodologia Científica}

\section{Metodologia}

A nossa investigação apresenta um modelo hipotético-dedutivo ${ }^{107}$. Significa que partimos de um modelo, criando uma hipótese. Temos consciência de que nos

\footnotetext{
107 «A construção parte de um postulado ou conceito postulado como modelo de interpretação do fenómeno estudado. Este modelo gera, através de um trabalho lógico, hipóteses, conceitos e indicadores para os quais se terão de procurar correspondentes no real.» CAMPENHOUDT LucVan,
} 
encontramos em "terreno novo", pois o trabalho académico na área da consultoria filosófico é escasso. ${ }^{108}$

A metodologia a utilizar insere-se numa abordagem de índole quantitativa, recorrendo ao inquérito por questionário de forma a aferir se as necessidades filosóficas definidas se manifestam no contexto do trabalho.

No sentido de enriquecer o trabalho e a proporcionar uma leitura mais ampla deste tema, cujos estudos escasseiam no nosso país, realizámos algumas entrevistas de tipo semi-estruturado.

Conjugamos, desta forma, uma metodologia com dois tipos de análise: quantitativa (inquéritos por questionário) e qualitativa (entrevistas). ${ }^{109}$

\section{Instrumentos de recolha de dados}

A utilização do inquérito por questionário ${ }^{110}$ teve como objectivo conhecer a população activa, os colaboradores ou recursos humanos inseridos em E/O, no que respeita às necessidades filosóficas. Considerámos que o inquérito iria darnos a conhecer aquilo que as pessoas conhecem, ou não, da consultoria filosófica e da Filosofia Aplicada. ${ }^{111}$ Trata-se de um meio para apurar o que é necessário fazer de forma a divulgar esta temática.

Por sua vez, a entrevista semi-estruturada serviu para apurar a postura das pessoas face à questão das necessidades filosóficas, bem como perante a figura do filósofo e a sua presença no meio empresarial / organizacional. Pretendemos explorar aspectos relacionados com as vivências dos inquiridos no seu local de trabalho e que se relacionem com a nossa hipótese relativamente à existência de necessidades filosóficas, junto dos recursos humanos. Segundo Quivy ${ }^{112}$, este método permite-nos aceder à "análise de sentido que os actores dão às suas práticas e aos acontecimentos com os quais se vêem confrontados".

QUIVY Raymond. - Manual de Investigação em Ciências Sociais. - Lisboa: Gradiva, 2008, $5^{\mathrm{a}}$ edição, p. 144

108 Esta escassez encontra-se na área da consultoria filosófica, bem como no cruzamento dos Recursos Humanos com a Filosofia Aplicada.

${ }^{109}$ Realizámos uma análise de conteúdo às entrevistas, por considerarmos pertinente para o estudo em geral: «O lugar ocupado pela análise de conteúdo na investigação é cada vez maior, nomeadamente porque oferece a possibilidade de tratar de forma metódica informações e testemunhos que apresentam um certo grau de profundidades e de complexidade, como, por exemplo, os relatórios de entrevistas(...)»CAMPENHOUDT LucVan, QUIVY Raymond - Op. Cit. - p. 227.

De forma a ilustrar o tratamento do questionário (de índole quantitativa), optámos por utilizar as entrevistas como complemento dos resultados dos questionários.

${ }^{110} \mathrm{O}$ questionário, na sua versão em Word, encontra-se no Anexo D.

${ }^{111}$ Op. Cit., p. 189.

${ }^{112}$ Op. Cit., p. 193. 


\section{Objecto de estudo}

O nosso universo de estudo ${ }^{113}$ abrange todas as pessoas que fazem parte da população activa. Pretendíamos uma amostra o mais transversal possível, procurando agregar pessoas de idades diferenciadas, bem como sexo, estado civil e profissões. Porquê? Por considerarmos que as necessidades filosóficas são intrínsecas aos seres humanos, independentemente desses factores.

Tendo em conta que o nosso universo alvo diz respeito a uma grande parte da população, procurámos construir um universo inquirido significativo, utilizando para o efeito a divulgação do questionário através das redes sociais. ${ }^{114}$ Estamos confiantes de que esta opção foi a mais acertada, tendo em conta o tempo disponível ${ }^{115}$ para a conclusão da tese.

\section{Técnicas de recolha de informaçãol: $O$ questionário}

De forma a estudarmos a questão das necessidades filosóficas das pessoas nas $\mathrm{E} / \mathrm{O}$, bem como o papel do consultor filosófico nestas, elaborámos um questionário que nos permitisse auscultar aquilo que as pessoas sentem e pensam sobre estas temáticas.

Dividimos o questionário em quatro partes, de acordo com as quatro necessidades filosóficas por nós elencadas no ponto 2.4.1. do presente trabalho. Todavia, para os inquiridos, o questionário surgia como um só, sem conter sequer a indicação das necessidades filosóficas em estudo. ${ }^{116}$ No final do questionário, apresentámos algumas questões abertas, que incidiam sobre o papel do consultor filosófico e da filosofia junto das empresas e organizações.

${ }^{113}$ Cf. HILL Andrew, HILL Manuela Magalhães. - Investigação por questionário. - Lisboa: Edições Sílabo, 2009, $2^{a}$ edição, p. 44.

${ }^{114}$ A utilização das redes sociais permitiu-nos difundir o questionário para lá da nossa própria rede. Através do Twitter, do Facebook e do recente Google +, propagámos o questionário pelas redes. Desta forma, chegámos a pessoas que não nos conhecem directamente, nem ao nosso trabalho no âmbito da Filosofia Aplicada.

${ }^{115}$ Devido a um problema de saúde, os nossos trabalhos sofreram um atraso de mês e meio/dois meses. Quando conseguirmos restabelecer-nos de forma a dar continuidade à dissertação, faltavam apenas dois meses para o término do prazo de entrega.

${ }^{116}$ Elaborámos um primeiro questionário, tendo solicitado a algumas pessoas que nos facultassem feedback sobre o mesmo (em termos de linguagem, das opções apresentadas para resposta). Esse questionário identificava as necessidades filosóficas, o que nos foi apontado como elemento perturbador da leitura do mesmo e condicionante do tipo de resposta. Tendo em conta este feedback, retirámos essa indicação.

Este questionário de teste foi enviado a um total de 15 pessoas.

Cf. CAMPENHOUDT LucVan, QUIVY Raymond. - Op. Cit. - p. 173. 
O questionário foi disponibilizado online ${ }^{117}$, de forma a construir uma amostra $^{118}$ aleatória, fruto do acaso. Partimos com um objectivo de angariar, no mínimo, cinquenta questionários ${ }^{119}$ para tratamento estatístico ${ }^{120}$. Ao fim de três dias já tínhamos recolhido cerca de cento e vinte e seis, graças à divulgação via redes sociais. No final de cinco dias, ultrapassámos a barreira dos duzentos.

Optámos por apresentar quatro hipóteses de escolha (nas questões fechadas):

1. discordo

2. concordo

3. é-me indiferente

4. nunca pensei sobre isso

As opções 1 e 2 seguem a linha do Professor Óscar Brenifier que defende a necessidade de escolha entre o sim e o não. Ou é preto ou é branco: para Brenifier não existem cinzentos. Mas considerámos a hipótese de haver uma "escolha cinzenta", em duas linhas: a resposta que nos diz que o inquirido tem uma postura passiva perante o assunto (é-me indiferente) e a resposta que denuncia a falta de consciência perante o assunto e eventualmente o desejo de iniciar um processo de pensamento sobre a temática em questão (nunca pensei sobre isso). ${ }^{121}$

117Para a realização do questionário utilizámos os formulários disponíveis no Google Docs: https://spreadsheets.google.com/spreadsheet/viewform?formkey=dGRYOVRUOTZyNmlBTDNFSk 1hWi04Y1E6MQ

${ }^{118}$ Segundo Hill, utilizámos o «caminho de esforço mínimo». Procurámos «obter uma amostra de tamanho ou dimensão tão grande quanto possível dentro dos limites de recursos disponíveis.» Cf. HILL Andrew, HILL Manuela Magalhães. - Op. Cit. - p. 53.

${ }^{119}$ Era essa a nossa intenção, quando apresentámos o projecto em Março último. Todavia, o júri alertou-nos para a pobreza da amostra e aconselhou-nos a duplicar ou triplicar esse número.

${ }^{120}$ Para o efeito utilizámos o programa SPSS. Aproveitamos para agradecer à Professora Ana Brochado pelo acompanhamento nesta parte do trabalho.

${ }^{121}$ Por se tratar de uma tese que funde a área da Filosofia Aplicada com os Recursos Humanos, procurámos a construção de um questionário que se cumprisse enquanto exercício de filosofia aplicada, permitindo que os inquiridos tomassem consciência do seu pensamento perante a pergunta, ao invés de simplesmente escolher entre um discordo em parte ou um concordo totalmente (por $\mathrm{ex}^{\mathrm{o}}$.). Consideramos que o nosso objectivo foi cumprido, pois tivemos várias reacções deste tipo, por exemplo, na plataforma Twitter: «o questionário fez pensar»; «tive que parar para pensar, mas foi um exercício interessante». Para que o exercício de Filosofia Aplicada fosse explorado até ao limite, seria necessário procurar os porquês de todas as afirmações defendidas pelos inquiridos. Consideramos que esta não seria a altura ideal para levar a cabo esse exercício; todavia, consideramos que o presente questionário pode ser, no futuro e mediante algumas alterações, utilizado como um instrumento para o consultor filosófico, num primeiro momento de um projecto de implementação da Filosofia nas E/O.

Este questionário acaba por dar continuidade ao trabalho que já havíamos começado em 2005, com a proposta de perfil de competências do consultor e consequente implementação de projecto de consultoria filosófica (na altura, denominada de consultoria espiritual). Cfr. notas de rodapé $\mathrm{n}^{\mathrm{o}} 3,18$ e 19. 
O questionário foi disponibilizado a 9 de Julho de 2011 e foi fechado a 15 de Julho, tendo obtido nessa data um total de 232 respostas. No gráfico que se segue podemos observar a forma como o número de respostas evoluiu nesse período de tempo.

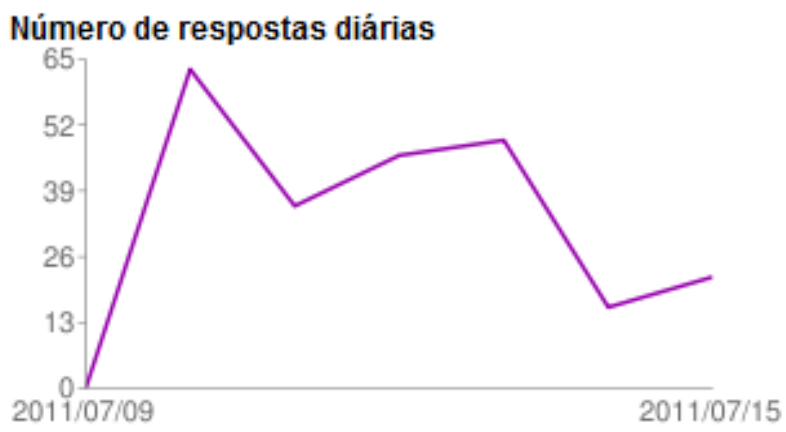

ILUSTRAÇÃO 3 - NÚMERO DE RESPOSTAS DIÁRIAS AO QUESTIONÁRIO [FONTE: GOOGLE DOCS]

Técnicas de recolha de informaçãolI: As Entrevistas

No que respeita às entrevistas semi-estruturadas, a nossa aposta inicial foi a da diversidade: de idade, sexo, profissão. Todavia, tivemos alguma dificuldade em encontrar quem estivesse disponível para a entrevista. De forma a evitar deslocações e para permitir que os entrevistados respondessem com calma, reflectindo sobre os tópicos, optámos por enviar a entrevista por e-mail

Conseguimos reunir quatro entrevistas, tendo contactado seis pessoas ${ }^{122}$ para o efeito. As entrevistas foram enviadas no princípio do mês de Julho de 2011, tendo sido solicitada a sua devolução até ao dia 15 de Julho.

\footnotetext{
${ }^{122}$ A escolha dos entrevistados aconteceu de diversas formas: através do Twitter e do Facebook, bem como dos nossos contactos de e-mail; a única condição era que as pessoas fizessem parte da população activa (tal como aconteceu com os questionários). Houve seis pessoas que se mostraram interessadas em colaborar, mas apenas quatro acabaram por devolver as entrevistas atempadamente.
} 


\section{Caracterização da amostra}

No que respeita aos questionários, a amostra constitui-se de 232 indivíduos, sendo a sua maioria mulheres (56\%). A maior concentração de idades revela-se entre os 31 e os 40 anos (42\%). 63\% dos inquiridos indicaram possuir bacharelato ou licenciatura, nenhum referiu habilitações literárias até ao $9^{\circ}$ ano. A grande maioria encontra-se no mercado de trabalho há mais de 10 anos (55\%) e apenas 3\% indicou estar no mercado de trabalho há menos de um ano. A maioria dos inquiridos encontra-se a trabalhar na área da educação / formação $(26,3 \%) ; 14,7 \%$ dos indivíduos indicaram pertencer à área do comércio / indústria. Quando perguntados pela função ${ }^{123}$ que desempenham na $\mathrm{E} / \mathrm{O}$, apurámos $18,5 \%$ de respostas na função assistente de cliente / assistente administrativo, 15,1\% nas funções professor / educador / formador, 11,2\% como técnico e 9,5\% como director / administrador.

A tabela 1 permite-nos uma leitura sucinta da amosta.

\begin{tabular}{|c|c|c|c|}
\hline \multirow[b]{2}{*}{ Variável } & \multirow[b]{2}{*}{ Categoria } & \multicolumn{2}{|c|}{ Frequência } \\
\hline & & Absoluta & Relativa (\%) \\
\hline \multirow{2}{*}{ Sexo } & Feminino & 130 & 56 \\
\hline & Masculino & 102 & 44 \\
\hline \multirow{5}{*}{ Idade } & entre 18 e 25 anos & 15 & 6 \\
\hline & entre 26 e 30 anos & 64 & 28 \\
\hline & entre 31 e 40 anos & 98 & 42 \\
\hline & entre 41 e 45 anos & 15 & 6 \\
\hline & mais de 45 anos & 40 & 17 \\
\hline \multirow{4}{*}{$\begin{array}{c}\text { Habilitações } \\
\text { Literárias }\end{array}$} & até ao $9^{\circ}$ ano & 0 & 0 \\
\hline & do $10^{\circ}$ ao $12^{\circ}$ ano & 48 & 21 \\
\hline & bacharelato/licenciatura & 145 & 63 \\
\hline & mestrado & 36 & 16 \\
\hline
\end{tabular}

${ }^{123}$ Esta pergunta encontrava-se em aberto, tendo sido obtidas várias respostas diferentes. Foi necessário, a posteriori, proceder ao agrupamento das funções, consoante a frequência com que se repetiam. Apurámos doze funções com uma frequência significativa, que totalizam $82,8 \%$ do total da amostra. 


\begin{tabular}{|c|c|c|c|}
\hline & doutoramento & 3 & 1 \\
\hline \multirow{6}{*}{$\begin{array}{l}\text { Há quanto tempo está } \\
\text { inserido no mercado } \\
\text { de trabalho? }\end{array}$} & menos de 1 ano & 8 & 3 \\
\hline & entre 1 a 3 anos & 15 & 15 \\
\hline & entre 3 a 5 anos & 23 & 10 \\
\hline & entre 5 a 7 anos & 23 & 10 \\
\hline & entre 7 a 10 anos & 35 & 35 \\
\hline & há mais de 10 anos & 128 & 55 \\
\hline \multirow{10}{*}{$\begin{array}{c}\text { Área em que se insere } \\
\text { a empresa/ } \\
\text { organização? }\end{array}$} & Educação/Formação & 61 & 26,3 \\
\hline & Media/Telecomunicações & 28 & 12,1 \\
\hline & Banca/Seguros & 17 & 7,3 \\
\hline & Comércio/Indústria & 34 & 14,7 \\
\hline & Consultoria/Gestão & 20 & 8,6 \\
\hline & Turismo/Hotelaria & 3 & 1,3 \\
\hline & Construção & 9 & 3,9 \\
\hline & Saúde & 16 & 6,9 \\
\hline & Administração Pública & 19 & 8,2 \\
\hline & Outras & 25 & 10,8 \\
\hline \multirow{11}{*}{$\begin{array}{c}\text { Qual é a função que } \\
\text { desempenha na } \\
\text { empresa/organização? }\end{array}$} & Gestor & 17 & 7,3 \\
\hline & Jornalista & 7 & 3 \\
\hline & $\begin{array}{l}\text { Assistente de } \\
\text { cliente/assistente } \\
\text { administrativo }\end{array}$ & 43 & 18,5 \\
\hline & Investigador & 9 & 3,9 \\
\hline & Técnico & 26 & 11,2 \\
\hline & Coordenador & 14 & 6 \\
\hline & Empresário & 5 & 2,2 \\
\hline & Professor/Educador/Formador & 35 & 15,1 \\
\hline & Consultor & 5 & 2,2 \\
\hline & Director/Administrador & 22 & 9,5 \\
\hline & Advogado & 3 & 1,3 \\
\hline
\end{tabular}


TABELA 1 - CARACTERIZAÇÃO DA AMOSTRA (QUESTIONÁRIOS)

Relativamente às quatro entrevistas realizadas, três dos nossos entrevistados eram mulheres, com idades compreendidas entre os 31 e os 49 anos; três indicaram ter mestrado e apenas um o bacharelato/licenciatura. Todos indicaram encontrar-se no mercado de trabalho há mais de dez anos e as áreas das E/O indicadas foram educação/formação, comércio/indústria e banca/seguros (cfr. tabela 2).

\begin{tabular}{|c|c|c|c|c|c|c|}
\hline Inquiridos & Sexo & Idade & $\begin{array}{c}\text { Habilitações } \\
\text { Literárias }\end{array}$ & $\begin{array}{c}\text { Há } \\
\text { quanto } \\
\text { tempo } \\
\text { está } \\
\text { inserido } \\
\text { no } \\
\text { mercado } \\
\text { de } \\
\text { trabalho? }\end{array}$ & $\begin{array}{c}\text { Área em } \\
\text { que se } \\
\text { insere a } \\
\text { E/O? }\end{array}$ & $\begin{array}{c}\text { Qual é a } \\
\text { função que } \\
\text { desempenha } \\
\text { na E/O? }\end{array}$ \\
\hline A & $\mathrm{F}$ & $\begin{array}{c}\text { entre } \\
31 \mathrm{e} \\
34 \\
\end{array}$ & Mestrado & $\begin{array}{c}\text { há mais } \\
\text { de } 10 \\
\text { anos }\end{array}$ & $\begin{array}{c}\text { Educação } \\
/ \\
\text { Formação }\end{array}$ & $\begin{array}{c}\text { formadora na } \\
\text { área } \\
\text { comportamenta }\end{array}$ \\
\hline B & M & $\begin{array}{c}\text { entre } \\
31 \mathrm{e} \\
34\end{array}$ & Mestrado & $\begin{array}{c}\text { há mais } \\
\text { de } 10 \\
\text { anos }\end{array}$ & $\begin{array}{c}\text { Comércio } \\
/ \\
\text { Indústria }\end{array}$ & $\begin{array}{l}\text { director do } \\
\text { centro de } \\
\text { produção }\end{array}$ \\
\hline $\mathrm{C}$ & $\mathrm{F}$ & $\begin{array}{c}\text { entre } \\
35 \mathrm{e} \\
40\end{array}$ & Mestrado & $\begin{array}{c}\text { há mais } \\
\text { de } 10 \\
\text { anos }\end{array}$ & $\begin{array}{l}\text { Banca / } \\
\text { Seguros }\end{array}$ & $\begin{array}{l}\text { intranet } \\
\text { manager }\end{array}$ \\
\hline D & $\mathrm{F}$ & $\begin{array}{c}\text { entre } \\
35 \mathrm{e} \\
40\end{array}$ & $\begin{array}{c}\text { Bacharelato } \\
\text { / } \\
\text { Licenciatura }\end{array}$ & $\begin{array}{c}\text { há mais } \\
\text { de } 10 \\
\text { anos }\end{array}$ & $\begin{array}{c}\text { Comércio } \\
/ / \\
\text { Indústria }\end{array}$ & $\begin{array}{c}\text { técnico superior } \\
\text { de recursos } \\
\text { humanos }\end{array}$ \\
\hline
\end{tabular}

TABELA 2 - CARACTERIZAÇÃO DOS ENTREVISTADOS 


\section{Apresentaçao dos resultados}

\section{Necessidades Filosóficas: Necessidade de inquisição/questionamento}

As questões relativas à necessidade de inquisição/questionamento encontravamse entre os números 1 e 9.

Conforme se pode apurar na tabela 3 , colocar em causa procedimentos (pergunta 1) é algo com o qual 95,7\% dos inquiridos concorda. A percentagem de "indiferentes" é tão baixa como a dos que responderam que nunca tinham pensado sobre o assunto $(1,7 \%)$.

A valorização do perguntar encontra-se bastante sublinhada na questão 4 (para compreender melhor o que me dizem faço muitas perguntas), com 70,3\% de inquiridos a concordar. 23,3\% discordam dessa postura interrogativa. $88,4 \%$ dos inquiridos afirmam que não precisam que lhes expliquem muitas vezes a mesma coisa (pergunta 3); a compreensão da tarefa é fundamental para que 87,5\% dos inquiridos apresentem um bom desempenho na sua execução (pergunta 2). Relativamente às reuniões de trabalho (pergunta 4), 70,3\% concordam que estas constituam espaços para comunicar ideias; na pergunta 6 , $96 \%$ dos inquiridos referem a importância de haver um espaço para as questões, nas reuniões. ${ }^{124}$

O questionamento é aqui valorizado pela maioria dos indivíduos (pergunta 7). $98,3 \%$ dos indivíduos afirmam concordar com "pensar sobre aquilo que estamos a fazer pode melhorar o nosso desempenho". Relativamente a esta questão, nenhum dos indivíduos respondeu "nunca pensei sobre o assunto".

Quando questionados sobre o conhecimento que têm do seu papel na empresa (pergunta 8), 14,7\% revelam não conhecer e 80,2\% afirmam que conhecem. 3\% dos inquiridos revelaram que este tópico lhes é indiferente.

Quanto ao papel da caixa de sugestões como uma possibilidade de contributo dos colaboradores junto da empresa, $15,5 \%$ revelou nunca ter pensado sobre isso, $11,6 \%$ consideram que lhes é indiferente; $9,9 \%$ discorda e a maioria concorda $(62,9 \%)$.

Estes resultados podem ser observados na tabela que se segue $\left(n^{\circ} 3\right)$.

\footnotetext{
${ }^{124}$ No âmbito da Filosofia Aplicada, consideramos que ficou uma questão por avaliar, por parte dos inquiridos: «Na minha empresa, as reuniões de trabalho apresentam um espaço específico para as questões.».

Utilizando este questionário como uma ferramenta de levantamento de necessidades, por parte do consultor filosófico, há que apurar este tipo de avaliações e considerações do colaborador perante a E/O onde se encontra.
} 


\begin{tabular}{|c|c|c|c|c|}
\hline Questão & Discordo & Concordo & $\begin{array}{c}\text { É-me } \\
\text { indiferente }\end{array}$ & $\begin{array}{c}\text { Nunca pensei } \\
\text { sobre } 0 \\
\text { assunto }\end{array}$ \\
\hline $\begin{array}{l}\text { 1. Há procedimentos } \\
\text { que devem ser } \\
\text { colocados em causa }\end{array}$ & $2(0,9 \%)$ & $\begin{array}{c}222 \\
(95,7 \%)\end{array}$ & $4(1,7 \%)$ & $4(1,7 \%)$ \\
\hline $\begin{array}{l}\text { 2. Para desempenhar } \\
\text { bem a tarefa, tenho } \\
\text { que a compreender a } \\
100 \% \text {. }\end{array}$ & $\begin{array}{c}23 \\
(9,9 \%)\end{array}$ & $\begin{array}{c}203 \\
(87,5 \%)\end{array}$ & $4(1,7 \%)$ & $2(0,9 \%)$ \\
\hline $\begin{array}{l}\text { 3. Não preciso que } \\
\text { me expliquem muitas } \\
\text { vezes a mesma coisa. }\end{array}$ & $\begin{array}{c}21 \\
(9,1 \%)\end{array}$ & $\begin{array}{c}205 \\
(88,4 \%)\end{array}$ & $6(2,6 \%)$ & \\
\hline $\begin{array}{l}\text { 4. Para compreender } \\
\text { melhor o que me } \\
\text { dizem, faço muitas } \\
\text { perguntas }\end{array}$ & $\begin{array}{c}54 \\
(23,3 \%)\end{array}$ & $\begin{array}{c}163 \\
(70,3 \%)\end{array}$ & $9(3,9 \%)$ & $6(2,6 \%)$ \\
\hline $\begin{array}{l}\text { 5. As reuniões de } \\
\text { trabalho são espaços } \\
\text { para comunicar } \\
\text { ideias. }\end{array}$ & $\begin{array}{c}22 \\
(9,5 \%)\end{array}$ & $\begin{array}{c}204 \\
(87,9 \%)\end{array}$ & $5(2,2 \%)$ & $1(0,4 \%)$ \\
\hline $\begin{array}{l}\text { 6. As reuniões de } \\
\text { trabalho devem ter } \\
\text { um espaço para as } \\
\text { questões. }\end{array}$ & $5(2,2 \%)$ & $\begin{array}{c}223 \\
(96,1 \%)\end{array}$ & $2(0,9 \%)$ & $2(0,9 \%)$ \\
\hline $\begin{array}{l}\text { 7. Pensar sobre aquilo } \\
\text { que estamos a fazer } \\
\text { pode melhorar o } \\
\text { nosso desempenho }\end{array}$ & $1(0,4 \%)$ & $\begin{array}{c}228 \\
(98,3 \%)\end{array}$ & $3(1,3 \%)$ & \\
\hline $\begin{array}{l}\text { 8. Conheço } \\
\text { perfeitamente o meu } \\
\text { papel na empresa. }\end{array}$ & $\begin{array}{c}34 \\
(14,7 \%)\end{array}$ & $\begin{array}{c}186 \\
(80,2 \%)\end{array}$ & $7(3 \%)$ & $5(2,2 \%)$ \\
\hline $\begin{array}{l}\text { 9. A existência de } \\
\text { uma caixa de } \\
\text { sugestões permite o } \\
\text { contributo dos } \\
\text { colaboradores junto } \\
\text { da empresa. }\end{array}$ & $\begin{array}{c}23 \\
(9,9 \%)\end{array}$ & $\begin{array}{c}146 \\
(62,9 \%)\end{array}$ & $27(11,6 \%)$ & $36(15,5 \%)$ \\
\hline
\end{tabular}

TABELA 3 - NECESSIDADE DE INQUISIÇÃO / QUESTIONAMENTO 
Um dos entrevistados caracterizou o questionamento na sua empresa da seguinte forma: "Na minha empresa existem dois tipos questionamento, o aleatório e espontâneo, [o primeiro diz respeito ao] contacto diário entre as diversas hierarquias, sendo uma forma muito dinâmica resolução de problemas. [o segundo] através de reuniões programadas onde se fazem debates de ideias e pensamento organizacionais."

Decidimos cruzar as questões 3 e 4 . Utilizando a técnico do qui-quadrado, testámos a seguinte hipótese: Afirmar que "não preciso que me expliquem muitas vezes a mesma coisa" é independente de afirmar que "para compreender melhor o que me dizem faço muitas perguntas". Concluímos que não há razões para rejeitar a hipótese, pois o resultado de $\mathrm{p}=0,280$, ou seja é > a 0,05. As variáveis são, por isto, independentes.

\begin{tabular}{|c|c|c|c|c|c|c|}
\hline & & \multicolumn{4}{|c|}{$\begin{array}{l}\text { [4. Para compreender melhor o que me dizem, faço muitas } \\
\text { perguntas.] }\end{array}$} & \multirow[b]{2}{*}{ Total } \\
\hline & & 1 discordo & 2 concordo & $\begin{array}{c}3 \text { é-me } \\
\text { indiferente }\end{array}$ & $\begin{array}{c}4 \text { nunca } \\
\text { pensei sobre } \\
0 \text { assunto } \\
\end{array}$ & \\
\hline \multirow{3}{*}{$\begin{array}{l}\text { [3. Nẫo preciso que me } \\
\text { expliquem muitas vezes a } \\
\text { mesma coisa.] }\end{array}$} & 1 discordo & 3 & 18 & 0 & 0 & 21 \\
\hline & 2 concordo & 51 & 140 & 8 & 6 & 205 \\
\hline & 3 é-me indiferente & 0 & 5 & 1 & 0 & 6 \\
\hline \multicolumn{2}{|l|}{ Total } & 54 & 163 & 9 & 6 & 232 \\
\hline
\end{tabular}

TABELA 4 - QUI-QUADRADO [VARIÁVEIS 3 E 4]

Chi-Square Tests

\begin{tabular}{|l|r|r|r|}
\hline & \multicolumn{1}{|c|}{ Value } & df & \multicolumn{1}{c|}{$\begin{array}{c}\text { Asymp. Sig. } \\
\text { (2-sided) }\end{array}$} \\
\hline Pearson Chi-Square & $7,459^{a}$ & 6 &, 280 \\
Likelihood Ratio & 9,275 & 6 &, 159 \\
N of Valid Cases & 232 & & 6 \\
\hline
\end{tabular}

a. 7 cells $(58,3 \%)$ have expected count less than 5 . The minimum expected count is, 16 .

TABELA 5 - QUI-QUADRADO [VARIÁVEIS 3 E 4] 
Necessidades Filosóficas: Necessidade de diálogo versus escuta activa

87,5\% dos inquiridos admite que as reuniões são momentos que permitem conhecer as ideias dos colegas (pergunta 10). 8,2\% discorda e 2,6\% consideram que tal situação lhes é indiferente. No que respeita à questão da rentabilidade das reuniões mediante a prática da escuta perante as ideias dos outros (pergunta 11), 95,3\% concorda. Apenas 2,6\% dos inquiridos discorda deste tópico.

Com quem é que os inquiridos têm mais à vontade para discutir as ideias? Com os colegas ou com a chefia (perguntas 12 e 13)? 84,9\% admite ter à vontade para discutir as ideias com os seus colegas e 10,8\% discorda desta afirmação. Relativamente à discussão com a chefia, as respostas afirmativas baixam um pouco, para 78,4\% e os "discordo" sobem para $17,7 \%$. Os inquiridos que manifestaram uma postura de indiferença perante estas duas questões apresentam uma percentagem maior no que respeita aos colegas $(3,4 \%)$ do que à chefia $(2,6 \%)$.

$68,5 \%$ admite que repara com frequência que as pessoas não sabem explicar o efeito prático das suas ideias (pergunta 15). $6 \%$ nunca tinha pensado nisso.

Reuniões de trabalho como perda de tempo (pergunta 14), por falta de escuta activa: neste tópico, 83,2\% discordam e 12,5\% concordam. Apenas 4,3\% se revela indiferente perante este tópico e ninguém denunciou nunca ter pensado sobre este assunto.

Quanto à questão 16, identificamos valores muito próximos entre o "discordo" e o "concordo". Significa isto que o número de inquiridos que sente que as ideias que partilha não são aproveitadas por falta de vontade $(45,3 \%) \mathrm{em}$ ouvi-los é idêntico ao número de inquiridos que admite não se sentir assim $(46,6 \%)$.

$\mathrm{Na}$ tabela 6 é possível averiguar os valores em detalhe.

\begin{tabular}{|l|c|c|c|c|}
\multicolumn{1}{|c|}{ Questão } & Discordo & Concordo & $\begin{array}{c}\text { É-me } \\
\text { indiferente }\end{array}$ & $\begin{array}{c}\text { Nunca } \\
\text { pensei } \\
\text { sobre o } \\
\text { assunto }\end{array}$ \\
\hline $\begin{array}{l}\text { 10. Os momentos de } \\
\text { reunião permitem-me } \\
\text { conhecer melhor as } \\
\text { ideias dos colegas. }\end{array}$ & $\begin{array}{c}19 \\
(8,2 \%)\end{array}$ & $\begin{array}{c}203 \\
(87,5 \%)\end{array}$ & $6(2,6 \%)$ & $4(1,7 \%)$ \\
\hline $\begin{array}{l}\text { 11. As reuniões seriam } \\
\text { mais proveitosas se as } \\
\text { pessoas ouvissem as }\end{array}$ & $6(2,6 \%)$ & $\begin{array}{c}221 \\
(95,3 \%)\end{array}$ & $4(1,7 \%)$ & $1(0,4 \%)$ \\
\hline
\end{tabular}




\begin{tabular}{|c|c|c|c|c|}
\hline ideias dos outros. & & & & \\
\hline $\begin{array}{l}\text { 12. Sinto-me à vontade } \\
\text { para discutir as ideias } \\
\text { com os meus colegas. }\end{array}$ & $\begin{array}{c}25 \\
(10,8 \%)\end{array}$ & $\begin{array}{c}197 \\
(84,9 \%)\end{array}$ & $8(3,4 \%)$ & $2(0,9 \%)$ \\
\hline $\begin{array}{l}\text { 13. Sinto-me à vontade } \\
\text { para discutir ideias com } \\
\text { a minha chefia }\end{array}$ & $\begin{array}{c}41 \\
(17,7 \%)\end{array}$ & $\begin{array}{c}182 \\
(78,4 \%)\end{array}$ & $6(2,6 \%)$ & $3(1,3 \%)$ \\
\hline $\begin{array}{l}14 \text { As reuniões são uma } \\
\text { perda de tempo, pois as } \\
\text { pessoas não se ouvem } \\
\text { umas às outras }\end{array}$ & $\begin{array}{c}193 \\
(83,2 \%)\end{array}$ & $\begin{array}{c}29 \\
(12,5 \%)\end{array}$ & $10(4,3 \%)$ & \\
\hline $\begin{array}{l}\text { 15. Reparo, com } \\
\text { frequência, que as } \\
\text { pessoas não sabem } \\
\text { explicar o efeito prático } \\
\text { da aplicação das suas } \\
\text { ideias }\end{array}$ & $58(25 \%)$ & $\begin{array}{c}159 \\
(68,5 \%)\end{array}$ & $1(0,4 \%)$ & $14(6 \%)$ \\
\hline $\begin{array}{l}\text { 16. Por vezes sinto que } \\
\text { as ideias que partilho não } \\
\text { são aproveitadas, porque } \\
\text { não me querem ouvir }\end{array}$ & $\begin{array}{c}105 \\
(45,3 \%)\end{array}$ & $\begin{array}{c}108 \\
(46,6 \%)\end{array}$ & $12(5,2 \%)$ & $7(3 \%)$ \\
\hline
\end{tabular}

TABELA 6 - NECESSIDADE DE DIÁLOGO VERSUS ESCUTA ACTIVA

Optámos por cruzar as questões 11 e 16. Através da técnica do qui-quadrado procurámos testar a hipótese: afirmar que as reuniões seriam mais proveitosas se as pessoas ouvissem as ideias dos outros é independente de afirmar que por vezes sinto que as ideias que partilho não são aproveitadas, porque não me querem ouvir. Somos obrigados a rejeitar a hipótese, pois o resultado de $\mathrm{p}=$ 0,005 , ou seja é < a 0,05. As variáveis são, assim, dependentes. 


\begin{tabular}{|c|c|c|c|c|c|c|}
\hline & & \multicolumn{4}{|c|}{$\begin{array}{l}\text { [16. Por vezes sinto que as ideias que partilho nẫo sẫo } \\
\text { aproveitadas, porque nẫo me querem ouvir.] }\end{array}$} & \multirow[b]{2}{*}{ Total } \\
\hline & & 1 discordo & 2 concordo & $\begin{array}{c}3 \text { é-me } \\
\text { indiferente } \\
\end{array}$ & $\begin{array}{c}4 \text { nunca } \\
\text { pensei sobre } \\
0 \text { assunto } \\
\end{array}$ & \\
\hline \multirow{4}{*}{$\begin{array}{l}\text { [11. As reuniônes seriam } \\
\text { mais proveitosas se as } \\
\text { pessoas ouvissem as } \\
\text { ideias dos outros.] }\end{array}$} & 1 discordo & 4 & 1 & 0 & 1 & 6 \\
\hline & 2 concordo & 99 & 106 & 10 & 6 & 221 \\
\hline & 3 é-me indiferente & 1 & 1 & 2 & 0 & 4 \\
\hline & $\begin{array}{l}4 \text { nunca pensei sobre } 0 \\
\text { assunto }\end{array}$ & 1 & 0 & 0 & 0 & 1 \\
\hline \multicolumn{2}{|l|}{ Total } & 105 & 108 & 12 & 7 & 232 \\
\hline
\end{tabular}

TABELA 7 - QUI-QUADRADO [VARIÁVEIS 11 E 16]

Chi-Square Tests

\begin{tabular}{|c|c|c|c|}
\hline & Value & $\mathrm{df}$ & $\begin{array}{c}\text { Asymp. Sig. } \\
\text { (2-sided) }\end{array}$ \\
\hline Pearson Chi-Square & $23,757^{a}$ & 9 &, 005 \\
\hline Likelihood Ratio & 13,053 & 9 &, 160 \\
\hline N of Valid Cases & 232 & & \\
\hline
\end{tabular}

a. 12 cells $(75,0 \%)$ have expected count less than 5 . The minimum expected count is, 03 .

TABELA 8 - QUI-QUADRADO [VARIÁVEIS 11 E 16]

Necessidades Filosóficas: Necessidade de perspectivas diferentes sobre a mesmidade

No que respeita às questões relacionadas com esta necessidade, salientamos 90,1\% de "concordo" perante a questão 21 (a rotina pode ser evitada se nos for dada a oportunidade de testar diferentes formas de execução dos processos), bem como $87,5 \%$ na questão 20 (prefiro conhecer alternativas que me permitam conhecer melhor a tarefa e o fim a que ela se destina).

Curioso é confrontar os "concordo" da questão 20 com a 19 (procurar alternativas que me permitam poupar tempo) e verificar que há um maior número de inquiridos que preferem as alternativas numa perspectiva de conhecimento da tarefa $(87,5 \%)$ do que propriamente para poupar tempo $(75,9 \%)$. 
Quanto à questão $17,85.3 \%$ dos inquiridos referiu que concorda e 5,2\% nunca pensou sobre este tópico (antes de iniciar uma tarefa, gosto de escolher a forma como me vou dedicar a ela).

\begin{tabular}{|c|c|c|c|c|}
\hline Questão & Discordo & Concordo & $\begin{array}{c}\text { É-me } \\
\text { indiferente }\end{array}$ & $\begin{array}{c}\text { Nunca pensei } \\
\text { sobre } 0 \\
\text { assunto }\end{array}$ \\
\hline $\begin{array}{l}\text { 17. Antes de } \\
\text { iniciar uma tarefa, } \\
\text { gosto de escolher a } \\
\text { forma como me } \\
\text { vou dedicar a ela. }\end{array}$ & $3(1,3 \%)$ & $\begin{array}{c}198 \\
(85,3 \%)\end{array}$ & $19(8,2 \%)$ & $12(5,2 \%)$ \\
\hline $\begin{array}{l}\text { 18. Os } \\
\text { procedimentos que } \\
\text { existem devem ser } \\
\text { seguidos. }\end{array}$ & $\begin{array}{c}73 \\
(31,5 \%)\end{array}$ & $\begin{array}{c}139 \\
(59,9 \%)\end{array}$ & $13(5.6 \%)$ & $7(3 \%)$ \\
\hline $\begin{array}{l}19 . \text { Prefiro } \\
\text { procurar } \\
\text { alternativas que me } \\
\text { permitam poupar } \\
\text { tempo. }\end{array}$ & $\begin{array}{c}40 \\
(17,2 \%)\end{array}$ & $\begin{array}{c}176 \\
(75,9 \%)\end{array}$ & $8(3,4 \%)$ & $8(3,4 \%)$ \\
\hline $\begin{array}{l}\text { 20. Prefiro } \\
\text { procurar } \\
\text { alternativas que me } \\
\text { permitam conhecer } \\
\text { melhor a tarefa e o } \\
\text { fim a que ela se } \\
\text { destina. }\end{array}$ & $\begin{array}{c}11 \\
(4,7 \%)\end{array}$ & $\begin{array}{c}203 \\
(87,5 \%)\end{array}$ & $10(4,3 \%)$ & $8(3,4 \%)$ \\
\hline $\begin{array}{l}\text { 21. A rotina pode } \\
\text { ser evitada se nos } \\
\text { for dada a } \\
\text { oportunidade de } \\
\text { testar diferentes } \\
\text { formas de } \\
\text { execução dos } \\
\text { processos. }\end{array}$ & $\begin{array}{c}12 \\
(5,2 \%)\end{array}$ & $\begin{array}{c}209 \\
(90,1 \%)\end{array}$ & $3(1,3 \%)$ & $8(3,4 \%)$ \\
\hline
\end{tabular}

TABELA 9 - NECESSIDADE DE PERSPECTIVAS DIFERENTES SOBRE A MESMIDADE 
No que respeita à questão $18,31,5 \%$ dos inquiridos discorda que os procedimentos que existem devam ser seguidos e 59,9\% concorda com essa afirmação. Segue-se a tabela 9 que nos apresenta os resultados detalhados.

\section{Necessidades Filosóficas: Necessidade de compreensão das convicções}

$88,4 \%$ dos indivíduos afirmam conhecer a missão da empresa (pergunta 22) e $81,9 \%$ afirmam conhecer os valores da sua empresa (pergunta 23). No que respeita à questão 24 , em que procuramos apurar se os inquiridos se identificavam com a missão da empresa, 18,1\% revelou discordar, 69,4\% concordam e 2,6\% consideram que este tópico lhes é indiferente. 3,4\% nunca pensaram sobre o assunto. Quanto à mesma questão, mas desta vez sobre os valores (pergunta 25) os resultados são relativamente idênticos aos da questão 24, apresentando uma percentagem maior de indivíduos que nunca pensaram sobre o assunto.

"Preciso de tempo para integrar as ideias que me são comunicadas": a maioria dos inquiridos discorda $(46,6 \%)$ e $13 \%$ concorda. Para 5,6\% dos inquiridos este assunto é-lhes indiferente (pergunta 26).

A indiferença também é significativa no que respeita ao tópico 27: 10,8\% dos inquiridos revela que lhes é indiferente o investimento de tempo que possam fazer para conhecer a empresa onde trabalham. $78 \%$ concordam com esta afirmação. Já no que respeita à questão 28 , em que procuramos apurar se para os inquiridos é importante perceber a forma como o seu trabalho contribui para a realização da missão da empresa, $95,7 \%$ concorda com esta afirmação e apenas $1,3 \%$ não concorda.

$62,5 \%$ dos nossos inquiridos admitem que a sua empresa é um espaço onde se sentem realizados e apenas $29,3 \%$ (pergunta 29) responde de forma negativa. Os indiferentes e os que não pensaram sobre o assunto somam uma percentagem de $8,1 \%$.

A tabela 10 permite-nos uma leitura detalhada das respostas relativas a esta necessidade filosófica.

\begin{tabular}{|l|c|c|c|c|}
\hline \multicolumn{1}{|c|}{ Questão } & Discordo & Concordo & $\begin{array}{c}\text { É-me } \\
\text { indiferente }\end{array}$ & $\begin{array}{c}\text { Nunca pensei } \\
\text { sobre o } \\
\text { assunto }\end{array}$ \\
\hline $\begin{array}{l}\text { 22. Conheço a } \\
\text { missão da minha } \\
\text { empresa. }\end{array}$ & $\begin{array}{c}17 \\
(7,3 \%)\end{array}$ & $\begin{array}{c}205 \\
(88,4 \%)\end{array}$ & $7(3 \%)$ & $3(1,3 \%)$ \\
\hline 23. Conheço os & 28 & 190 & $6(2,6 \%)$ & $8(3,4 \%)$ \\
\hline
\end{tabular}




\begin{tabular}{|c|c|c|c|c|}
\hline $\begin{array}{l}\text { valores da minha } \\
\text { empresa. }\end{array}$ & $(12,1 \%)$ & $(81,9 \%)$ & & \\
\hline $\begin{array}{l}\text { 24. Concordo com } \\
\text { a missão da minha } \\
\text { empresa e } \\
\text { identifico-me com } \\
\text { ela. }\end{array}$ & $\begin{array}{c}42 \\
(18,1 \%)\end{array}$ & $\begin{array}{c}161 \\
(69,4 \%)\end{array}$ & $18(7,8 \%)$ & $11(4,7 \%)$ \\
\hline $\begin{array}{l}\text { 25. Concordo com } \\
\text { os valores da } \\
\text { minha empresa e } \\
\text { identifico-me com } \\
\text { eles. }\end{array}$ & $\begin{array}{c}49 \\
(21,1 \%)\end{array}$ & $\begin{array}{c}151 \\
(65,1 \%)\end{array}$ & $19(8,2 \%)$ & $13(5,6 \%)$ \\
\hline $\begin{array}{l}\text { 26. Preciso de } \\
\text { tempo para } \\
\text { integrar as ideias } \\
\text { que me são } \\
\text { comunicadas. }\end{array}$ & $\begin{array}{c}108 \\
(46,6 \%)\end{array}$ & $107(13 \%)$ & $13(5,6 \%)$ & $4(1,7 \%)$ \\
\hline $\begin{array}{l}\text { 27. Gosto de } \\
\text { investir algum } \\
\text { tempo a conhcer a } \\
\text { empresa onde } \\
\text { trabalho. }\end{array}$ & $\begin{array}{c}15 \\
(6,5 \%)\end{array}$ & $181(78 \%)$ & $25(10,8 \%)$ & $11(4,7 \%)$ \\
\hline $\begin{array}{l}\text { 28. É importante } \\
\text { perceber a forma } \\
\text { como o meu } \\
\text { trabalho contribui } \\
\text { para a realização } \\
\text { da missão da } \\
\text { empresa. }\end{array}$ & $3(1,3 \%$ & $\begin{array}{c}222 \\
(95,7 \%)\end{array}$ & $4(1,7 \%)$ & $3(1,3 \%)$ \\
\hline $\begin{array}{l}\text { 29. A minha } \\
\text { empresa é um } \\
\text { espaço onde me } \\
\text { sinto realizado(a). }\end{array}$ & $\begin{array}{c}68 \\
(29,3 \%)\end{array}$ & $\begin{array}{c}145 \\
(62,5 \%)\end{array}$ & $11(4,7 \%)$ & $8(3,4 \%)$ \\
\hline
\end{tabular}

TABELA 10 - NECESSIDADE DE COMPREENSÃO DAS CONVICÇÕES

No que respeita à questão do conhecimento e identificação com a missão da empresa, os nossos entrevistados afirmam conhecer, mas nem todos se identificam com ela. Sublinhamos aqui uma das respostas: "Conheço. Identifico[-me]. Tento que tudo o que faço e a maneira como me comporto na 
empresa espelhem essa missão e os valores da empresa. O meu contributo para a empresa só é possível porque estou em consonância. No entanto, há questões práticas que vão surgindo que nem sempre concordo, mas é normal e isso não me coloca contra a missão da empresa. São pequenas divergências."

Quanto aos valores, os quatro entrevistados admitem conhecê-los e até discuti-los com os seus colegas e chefias, ainda que "de forma muito superficial, para não entrar em choque com as chefias (de forma equilibrada)."

Perguntamos também aos nossos entrevistados se uma empresa/organização existe para compreender os seus colaboradores e para ser compreendida por eles? Porquê? Todos afirmaram que sim, salientando que a " compreensão tem de ser mútua e equilibrada", valorizando a "Interacção entre a Empresa e seus Colaboradores, para que juntos atinjam seu propósito e "ganhem" todos". Um dos entrevistados refere ainda que: "Quando os colaboradores são envolvidos nos processos de decisão sentem-se valorizados e parte integrante do processo, o que conduz a uma maior motivação, satisfação, empenho e produtividade. Os colaboradores podem contribuir de forma muito rica ao nível do pensamento criativo, inovador, sendo uma mais-valia para a empresa."

Resolvemos testar a seguinte hipótese: afirmar que concordo com os valores da minha empresa e identifico-me com eles é independente de considerar a empresa como um espaço onde me sinto realizado (tópicos 25 e 29). Através do qui-quadrado apurámos que $\mathrm{p}=0,000$, ou seja, é $<$ a 0,05 , concluindo que as variáveis se revelam dependentes. Ou seja, somos obrigados a rejeitar a hipótese enunciada e a admitir que a afirmação do tópico 25 está dependente da afirmação do tópico 29. O facto dos indivíduos concordarem com os valores da sua empresa e de se identificarem com eles depende do facto da empresa constituir um espaço onde se sentem realizados.

\begin{tabular}{|c|c|c|c|c|c|c|}
\hline & & \multicolumn{4}{|c|}{ [29. A minha empresa é um espaço onde me sinto realizado(a).] } & \multirow[b]{2}{*}{ Total } \\
\hline & & 1 discordo & 2 concordo & $\begin{array}{c}\text { 3é-me } \\
\text { indifferente }\end{array}$ & $\begin{array}{c}4 \text { nunca } \\
\text { pensei sobre } \\
0 \text { assunto }\end{array}$ & \\
\hline \multirow{4}{*}{$\begin{array}{l}\text { [25. Concordo com os } \\
\text { valores da minha } \\
\text { empresa e identifico-me } \\
\text { com eles.] }\end{array}$} & 1 discordo & 32 & 14 & 3 & 0 & 49 \\
\hline & 2 concordo & 24 & 120 & 4 & 3 & 151 \\
\hline & 3 é-me indiferente & 7 & 7 & 3 & 2 & 19 \\
\hline & $\begin{array}{l}4 \text { nunca pensei sobre } 0 \\
\text { assunto }\end{array}$ & 5 & 4 & 1 & 3 & 13 \\
\hline Total & & 68 & 145 & 11 & 8 & 232 \\
\hline
\end{tabular}

TABELA 11 - QUI-QUADRADO [VARIÁVEIS 25 E 29] 
Chi-Square Tests

\begin{tabular}{|l|r|r|r|}
\hline & \multicolumn{1}{|c|}{ Value } & df & \multicolumn{1}{c|}{$\begin{array}{c}\text { Asymp. Sig. } \\
\text { (2-sided) }\end{array}$} \\
\hline Pearson Chi-Square & $78,384^{a}$ & 9 &, 000 \\
Likelihood Ratio & 68,106 & & 9 \\
N of Valid Cases & 232 & &, 000 \\
\hline
\end{tabular}

a. 7 cells $(43,8 \%)$ have expected count less than 5 . The minimum expected count is, 45 .

TABELA 12 - QUI-QUADRADO [VARIÁVEIS 25 E 29]

Filósofo na E/O? Em que área?

A pergunta 30 procurava saber junto dos inquiridos em que área da sua $\mathrm{E} / \mathrm{O}$ imaginaria um filósofo a trabalhar. Registamos 32,8\% de respostas indicando Departamento de Recursos Humanos. 4,7\% respondeu que não sabe e 3,9\% não respondeu a esta questão. 8,6\% afirmaram que não havia qualquer área onde o filósofo se pudesse integrar e 3\% indicou que o filósofo poderia estar em qualquer área. 5,2\% considera que o filósofo poderia estar ligado à área da formação; $4,3 \%$ à consultoria, 3,9\% à administração e 4,7\% ao marketing.

Os nossos entrevistados referiram, sem excepção, o Departamento de Recursos Humanos como área de integração do consultor filosófico; houve quem sugerisse, ainda, "todas as áreas", o departamento de marketing, a área de comunicação e a administração (topo).

$\mathrm{Na}$ tabela 13 podem ser observadas todas as respostas. 
Suponha que lhe comunicavam na E/O que seria recrutado um filósofo. Em que área da empresa o imagina a trabalhar?

\begin{tabular}{|c|c|c|c|c|c|}
\hline & & Frequency & Percent & Valid Percent & $\begin{array}{l}\text { Cumulative } \\
\text { Percent }\end{array}$ \\
\hline \multirow[t]{31}{*}{ Valid } & Administração & 9 & 3,9 & 3,9 & 3,9 \\
\hline & Assistente de direcção & 7 & 3,0 & 3,0 & 6,9 \\
\hline & $\mathrm{CEO}$ & 1 & ,4 & ,4 & 7,3 \\
\hline & Comunicação & 6 & 2,6 & 2,6 & 9,9 \\
\hline & Consultor & 10 & 4,3 & 4,3 & 14,2 \\
\hline & Criação de conteúdos & 7 & 3,0 & 3,0 & 17,2 \\
\hline & Cultura & 3 & 1,3 & 1,3 & 18,5 \\
\hline & $\begin{array}{l}\text { Departamento de Recursos } \\
\text { Humanos }\end{array}$ & 76 & 32,8 & 32,8 & 51,3 \\
\hline & Departamento Financeiro & 1 & ,4 & 4 & 51,7 \\
\hline & Desenvolvimento & 1 & ,4 & 4 & 52,2 \\
\hline & Docente & 4 & 1,7 & 1,7 & 53,9 \\
\hline & Em nenhuma área & 20 & 8,6 & 8,6 & 62,5 \\
\hline & Em todas as áreas & 7 & 3,0 & 3,0 & 65,5 \\
\hline & Estratégia & 6 & 2,6 & 2,6 & 68,1 \\
\hline & Eventos & 2 & ,9 & ,9 & 69,0 \\
\hline & Filosofia para Crianças & 2 & ,9 & ,9 & 69,8 \\
\hline & Formação & 12 & 5,2 & 5,2 & 75,0 \\
\hline & Gestão & 2 & ,9 & ,9 & 75,9 \\
\hline & Gestão de talento & 1 & 4 & 4 & 76,3 \\
\hline & Investigação & 3 & 1,3 & 1,3 & 77,6 \\
\hline & Limpeza & 1 & 4 & 4 & 78,0 \\
\hline & Marketing & 11 & 4,7 & 4,7 & 82,8 \\
\hline & Motivação & 2 & ,9 & ,9 & 83,6 \\
\hline & Mudança Organizacional & 1 & ,4 & 4 & 84,1 \\
\hline & Não respondeu & 9 & 3,9 & 3,9 & 87,9 \\
\hline & Não sabe & 11 & 4,7 & 4,7 & 92,7 \\
\hline & Planeamento & 6 & 2,6 & 2,6 & 95,3 \\
\hline & $\begin{array}{l}\text { Processo } \\
\text { Ensino/Aprendizagem }\end{array}$ & 1 & ,4 & 4 & 95,7 \\
\hline & Psicologia e Orientação & 4 & 1,7 & 1,7 & 97,4 \\
\hline & Relações Humanas & 6 & 2,6 & 2,6 & 100,0 \\
\hline & Total & 232 & 100,0 & 100,0 & \\
\hline
\end{tabular}

TABELA 13 - FILÓSOFO NA E/O: EM QUE ÁREA? 


\section{Filósofo na E/O? Benefícios?}

A pergunta 31 pretendia averiguar se os inquiridos consideravam benéfica a presença de um filósofo na sua E/O. Dos 232 inquiridos, $50 \%$ responderam que sim e outros $50 \%$ responderam que não.

A tabela 14 ilustra os resultados dos questionários.

Considera que poderia beneficiar da presença de um filósofo na sua empresa/organização?

\begin{tabular}{|ll|r|r|r|r|}
\hline & & & & \multicolumn{2}{|c|}{ Cumulative } \\
& & Frequency & Percent & Valid Percent & \multicolumn{2}{|c|}{ Percent } \\
\hline Valid & Não & 116 & 50,0 & 50,0 & 50,0 \\
& Sim & 116 & 50,0 & 50,0 & 100,0 \\
& Total & 232 & 100,0 & 100,0 & \\
\hline
\end{tabular}

TABELA 14 - QUESTÃO 30

Perguntámos, ainda, aos inquiridos que responderam SIM quais seriam os benefícios dessa presença. O questionamento é assinalado na pergunta 31.1. do questionário como uma mais-valia da presença do filósofo na empresa: "a colocação de algumas perguntas que poderiam levar a muitas respostas e/ou soluções"; "ajudar a desenvolver o pensamento crítico"; "[para] aprender a questionar o que nos é apresentado como verdades absolutas"; "o questionamento sobre práticas" - estes são alguns dos benefícios apresentados pelos nossos inquiridos. ${ }^{125}$

Outro dos benefícios do filósofo na empresa, o "trabalho" ao nível das relações interpessoais. Neste caso em concreto, esse trabalho parece ser mais "urgente" no que respeita ao relacionamento dos inquiridos com a sua chefia. ${ }^{126}$

\footnotetext{
${ }^{125}$ Não encontramos relações entre esta pergunta e as características como a idade, o sexo e as habilitações literárias. Os resultados do testes qui-quadrado levaram-nos a aceitar a hipótese de independência. Apresentamos estes outputs no Anexo G.

${ }^{126}$ Um dos inquiridos respondeu: «A presença de um filósofo seria uma mais-valia no que respeita a ouvir os colaboradores, sendo uma ponte entre os mesmos e as chefias; fazendo ambos pensarem e participarem mais activamente em prol do sucesso da empresa, no que respeita ao bom ambiente, satisfação pessoal, motivação e melhor funcionamento das tarefas em geral». Outra resposta que sublinha a questão do relacionamento: «[o filósofo enquanto] facilitador da comunicação entre colegas e chefias e departamentos.»
} 
Os inquiridos referiram, com frequência, a possibilidade do filósofo proporcionar diferentes pontos de vista, o que vem ao encontro desta necessidade filosófica. ${ }^{127}$

Elaborámos uma análise à resposta 31.1 tendo verificado as seguintes frequências de resposta:

\begin{tabular}{|c|c|}
\hline Benefício indicado & Frequência \\
\hline diferentes pontos de vista & 12 \\
\hline melhoria das relações interpessoais & 10 \\
\hline debate de ideias & 9 \\
\hline pensamento / reflexão crítica & 9 \\
\hline criatividade & 8 \\
\hline questionamento & 6 \\
\hline tomada de decisão & 6 \\
\hline comunicação & 5 \\
\hline mudança de ideias & 5 \\
\hline
\end{tabular}

TABELA 15 - BENEFÍCIOS DA PRESENÇA DO FILÓSOFO NA E/O [FREQUÊNCIAS DE RESPOSTA]

Colocámos esta questão na entrevista ${ }^{128}$ e obtivemos três "SIM" e um NÃO". No que respeita aos SIM, as justificações foram:

- "no sentido em que poderia dedicar algum tempo a trabalhar a auto e hetero-consciência o que me permitiria estar em melhoria contínua como pessoa e profissional";

- "no Departamento de recursos humanos para ajuda no recrutamento, acompanhamento dos colaboradores, organização de sessões sociais promovendo principalmente o debate de pensamentos. No Departamento de Marketing, tendo como principais funções a interligação entre sectores produtivos e comerciais, adequando activamente os objectivos da empresa à necessidade dos mercados";

- "Recursos Humanos, ligado à gestão estratégica da empresa e aos centros de tomada de decisão (administração, gabinete de estratégia). Consultor

\footnotetext{
${ }^{127}$ Passamos a transcrever algumas das respostas nos nossos inquiridos: «novas perspectivas sobre um assunto, sem vícios de forma», «a colocação de algumas perguntas que poderiam levar a muitas respostas e/ou soluções»; «[o filósofo] teria uma visão diferente da estrutura da empresa»; «pensamento divergente com novas ideias úteis para a empresa», «apresentar novas (ou diferentes) perspectivas de encarar uma determinada situação/desafio», entre outros.

${ }^{128}$ Cfr. Anexo E - Entrevistas.
} 
independente de qualquer área mas que apoia todas as áreas: desde chefias a operários".

O "NÃO" foi justificado da seguinte forma: "Actualmente com o tipo de Cultura na minha Empresa, não. Será necessário primeiro reconhecer a maisvalia que um Filosofo pode trazer a uma Estrutura./Organização/Empresa.”

\section{Filósofo na E/O? Conhece algum contributo?}

No que respeita à pergunta $32,71,1 \%$ dos inquiridos respondeu que nunca ouviu falar de contributos da filosofia para as empresas, $12,5 \%$ não respondeu a esta questão e apenas $16,4 \%$ respondeu afirmativamente (cfr. tabela 15).

Já ouviu falar de algum contributo da filosofia para as empresas (no geral)?

\begin{tabular}{|ll|r|r|r|r|}
\hline & Frequency & Percent & Valid Percent & \multicolumn{2}{c|}{$\begin{array}{c}\text { Cumulative } \\
\text { Percent }\end{array}$} \\
\hline Valid Não & 165 & 71,1 & 71,1 & 71,1 \\
& 29 & 12,5 & 12,5 & 83,6 \\
Não & & & & \\
respondeu & 38 & 16,4 & 16,4 & 100,0 \\
Sim & 232 & 100,0 & 100,0 & \\
Total & & & \\
\hline
\end{tabular}

TABELA 16 - QUESTÃO 31

Nas entrevistas, obtivemos dois "Não" e dois "SIM". Um dos entrevistados referiu mesmo o consultor filosófico: “(...) através da figura do consultor filosófico, o representante da filosofia dentro das empresas.”

\section{Algumas relações entre as necessidades filosóficas}

Resolvemos testar relações entre algumas variáveis, elencadas em diferentes necessidades filosóficas. Utilizámos a técnica do qui-quadrado, cujos outputs se encontram no Anexo F.

Verificámos independência entre a questão 1 (necessidade de inquisição/questionamento) e entre a questão 18 (necessidade de perspectivas diferentes sobre a mesmidade), bem como entre a questão 8 (necessidade de inquisição/questionamento) e a 28 (necessidade de compreensão das convicções). 
A dependência das variáveis verificou-se quando relacionámos a questão 8 necessidade de inquisição/questionamento) e a questão 29 (necessidade de compreensão das conviç̧ões). Esta mesma questão foi relacionada com a 13 (necessidade de diálogo versus escuta activa) e também se verificou dependência. Podemos, então, afirmar que o resultado é estatisticamente significante. O mesmo aconteceu ao testar as variáveis 16 e 29: fomos obrigados a rejeitar a hipótese.

A tabela 16 permite-nos uma leitura destas conclusões.

\begin{tabular}{|c|c|c|c|c|}
\hline Variável 1 & Variável 2 & $\mathrm{x} 2$ & p value & Resultado \\
\hline $\begin{array}{c}1 . \text { Há } \\
\text { procedimentos } \\
\text { que devem ser } \\
\text { colocados em } \\
\text { causa }\end{array}$ & $\begin{array}{l}\text { 18. Os procedimentos } \\
\text { que existem devem ser } \\
\text { seguidos. }\end{array}$ & \multirow{5}{*}{0,05} & 0,425 & aceitar Ho \\
\hline $\begin{array}{l}\text { 8. Conheço } \\
\text { perfeitamente o } \\
\text { meu papel na } \\
\text { empresa. }\end{array}$ & $\begin{array}{l}\text { 28. É importante } \\
\text { perceber a forma como } \\
\text { o meu trabalho } \\
\text { contribui para a } \\
\text { realizaçãoda missão da } \\
\text { empresa. }\end{array}$ & & 0,987 & aceitar Ho \\
\hline $\begin{array}{l}\text { 8. Conheço } \\
\text { perfeitamente o } \\
\text { meu papel na } \\
\text { empresa. }\end{array}$ & $\begin{array}{l}\text { 29. A minha empresa é } \\
\text { um espaço onde me } \\
\text { sinto realizado }\end{array}$ & & 0,04 & rejeitar Ho \\
\hline $\begin{array}{l}\text { 13. Sinto-me à } \\
\text { vontade para } \\
\text { discutir ideias } \\
\text { com a minha } \\
\text { chefia. } \\
\end{array}$ & $\begin{array}{l}\text { 29. A minha empresa é } \\
\text { um espaço onde me } \\
\text { sinto realizado }\end{array}$ & & 0 & rejeitar Ho \\
\hline $\begin{array}{l}\text { 16. Por vezes } \\
\text { sinto que as } \\
\text { ideias que } \\
\text { partilho não são } \\
\text { aproveitadas, } \\
\text { porque não me } \\
\text { querem ouvir. }\end{array}$ & $\begin{array}{l}\text { 29. A minha empresa é } \\
\text { um espaço onde me } \\
\text { sinto realizado }\end{array}$ & & 0 & rejeitar Ho \\
\hline
\end{tabular}

TABELA 17 - RELAÇÕES ENTRE NECESSIDADES FILOSÓFICAS 
Nas entrevistas foi possível detectar algumas relações entre as necessidades filosóficas; a propósito da importância do diálogo, diz-nos um dos entrevistados: "Considero muito importante e pertinente uma vez que a consciência de diversas alternativas [necessidade de perspectivas diferentes sobre a mesmidade] ajuda na tomada da melhor decisão. Além disso, todos os intervenientes na decisão se sentem valorizados e parte integrante do processo, o que conduz a uma maior motivação, satisfação, empenho e produtividade."

\section{Conclusões e recomendações}

\section{Da análise dos questionários e das entrevistas}

Os resultados obtidos no ponto "necessidade de inquisição/questionamento" revelam que os inquiridos valorizam o acto de perguntar e até mesmo o colocar os procedimentos em causa. $\mathrm{O}$ acto de pensar sobre aquilo que estamos a fazer e a consequente melhoria do nosso desempenho é frequentemente sublinhado pelos nossos inquiridos. É interessante assinalar uma das respostas à entrevista, relacionada com a inteligência emocional. Esta é apresentada como um elemento diferenciador na empresa, mas também como algo negativo: "o papel do raciocínio e da lógica ficaram completamente alterados (...) por vezes tomam-se decisões emocionais e não racionais." Efectivamente, o pensamento exige tempo. Será que as E/O dispõem de tempo para o diálogo, para o debate, prévio à tomada de decisão? O mesmo entrevistado revela: "em certos momentos, não existe tempo para o debate ou diálogo, sendo necessário tomar decisões imediatas, correndo alguns riscos." Poderá o filósofo agir na prevenção desse risco habilitando os decisores com ferramentas simples que lhes permitam, em pouco tempo, tomar a melhor decisão possível? José Manuel Fonseca assinala desta forma a necessidade das pessoas, no seio das E/O, em parar para pensar: "É que uma das coisas mais intrigantes com que o autor se tem deparado, enquanto consultor, consiste na recorrência da frase: "não consigo parar para reflectir tanto quanto seria desejável e necessário."129

Retomando os resultados dos inquiridos no que respeita à necessidade de diálogo e escuta activa, temos que salientar que 95,3\% dos inquiridos concorda que as reuniões seriam muito mais proveitosas se as pessoas ouvissem as ideias dos outros. Ou seja, a valorização atribuída ao debate/diálogo contrasta com este aspecto da prática que nos revela que há falta de escuta. Daí que metade dos

\footnotetext{
${ }^{129}$ FONSECA José Manuel. - O paradoxo da inovação empresarial. - p. 87
} 
inquiridos denuncie que sentem que as ideias que partilham não são aproveitadas porque não há quem as queira ouvir.

Consideramos que este seria outro campo de trabalho para o filósofo, um outro desafio: a promoção de debates de questionamento entre colaboradores, utilizando técnicas como as do Professor Óscar Brenifier de forma a averiguar se o processo de escuta efectivamente acontece. ${ }^{130}$

Relativamente às necessidades de perspectivas diferentes sobre a mesmidade, ${ }^{131}$ podemos concluir que os inquiridos valorizam as alternativas, numa perspectiva de evitar as rotinas. Esta necessidade é referida com bastante frequência nas entrevistas e é também sublinhada como motivo para a presença do filósofo na E/O por quem respondeu SIM à pergunta 31 do questionário.

Quanto à necessidade de compreensão das convicções ${ }^{132}$ encontramos associações entre o sentido de realização dos inquiridos na empresa e o facto de concordarem com os valores, de se identificarem com eles. Ou seja, se eu reconheço os valores da empresa como meus, mais facilmente me sentirei realizado por fazer parte dela. Compreender o que fazemos na empresa determina o sentido de realização. Seria interessante explorar esta necessidade filosófica com aspectos relacionados com a produtividade dos colaboradores, bem como com a motivação, a satisfação e o empenho (assim nos sugere um dos nossos entrevistados).

Verificamos que as pessoas não conhecem a finalidade, nem sequer o sentido do seu trabalho: os inquiridos admitiram a importância de conhecer o propósito do seu trabalho. ${ }^{133}$

É importante salientar as relações que se verificaram entre as necessidades filosóficas: a necessidade de questionamento e as perspectivas diferentes sobre a mesmidade, a questão da necessidade de compreensão das convicções e de diálogo e escuta activa, o questionamento e a necessidade de compreensão das convicções.

Gostaríamos ainda de sulbinhar o papel do questionamento, considerando esta necessidade como fundamental. A partir do momento em que a pessoa olhar para a realidade à sua volta e pergunta "porquê?", "como?", "mas não há outra forma de fazer isto?", inicia-se um processo de autonomia do pensar ao qual deverá ser dado forma através da investigação das perguntas que se colocam. É certo que nem sempre as empresas valorizam este tipo de atitude, mas também aí o filósofo poderá trabalhar: para mudar as atitudes das próprias empresas.

\footnotetext{
${ }^{130}$ Cfr. BRENIFIER Óscar - La pratique de la philosophie. - Toulose: Sedrap, 2007, pp. 32-40.

${ }^{131}$ Cfr. pontos 2.4.1.3. e 5.1.3. do presente trabalho.

${ }^{132}$ Cfr. pontos 2.4.1.4. e 5.1.4. do presente trabalho.

133 «As pessoas necessitam de certeza quanto ao que delas é esperado, e de saber qual é a escala que será utilizada na avaliação de desempenho.» FONSECA José Manuel. - Op. Cit. - p. 75.
} 
Perante a pergunta sobre os possíveis benefícios da presença de um filósofo na sua $E / O$, os inquiridos dividiram-se em igual número entre o Sim e o Não, inviabilizando qualquer conclusão positiva ou negativa.

As respostas à questão 30 do questionário e também às respostas dos entrevistados confirmam o papel do filósofo junto dos Recursos Humanos, A percentagem de pessoas que afirmaram que não havia qualquer área onde o filósofo se pudesse integrar é pouco expressiva (8,6\%). Todavia, somado esse resultado com os "não sabe" e os "não respondeu" totaliza 17,20\% da amostra. Para que a filosofia aplicada às E/O vingue é necessário contrariar esta tendência.

Não podemos deixar de sublinhar aqui uma das respostas de um dos entrevistados em que nos era indicado que seria necessária a mudança da cultura da empresa para que o filósofo pudesse fazer sentido dentro desta. Será o filósofo faz sentido em todos os tipos de E/O?

\section{Proposta: o consultor filosófico na E/O}

$\mathrm{O}$ papel do consultor filosófico nas $\mathrm{E} / \mathrm{O}$ diz respeito à orientação

(1) das pessoas nas $\mathrm{E} / \mathrm{O}$;

(2) das pessoas das $\mathrm{E} / \mathrm{O}$;

(3) e das pessoas e das E/O.

O filósofo poderá agir no sentido de criar sentido entre aquilo que as pessoas são e fazem nas E/O (1). O filósofo poderá, em articulação com os recursos humanos, construir elementos de trabalho (em alternativa, pode recorrrer a ferramentas já existentres) para que numa fase de recrutamento e selecção (por ex.) sejam escolhidos os candidatos cujo perfil abraça aquilo que a E/O efectivamente é. Para isso, é preciso também saber "quem é" a E/O e para onde caminha.

O consultor filosófico parte para a E/O com o objectivo de compreender quem são as pessoas que se encontram por lá e de procurar saber se há sintonia entre aquilo que as pessoas esperam da $\mathrm{E} / \mathrm{O}$ e o que a $\mathrm{E} / \mathrm{O}$ espera das pessoas. (2)

Por último (3), o filósofo pode fazer um trabalho com as pessoas (no âmbito empresarial) e com as E/O no sentido de trabalhar aspectos ligados a áreas tão diversas como aquelas apontadas pelos nossos inquiridos: departamento de recursos humanos, formação, consultoria, administração e marketing.

Tal orientação vai no sentido do encontro entre aquilo que se defende (teoria) e aquilo que efectivamente se faz (prática). O valor específico da consultoria filosófica encontra-se directamente ligado ao valor da própria filosofia, como ciência que estuda áreas tão diversas como a linguagem, a lógica, a hermenêutica, a metafísica e a ética. $O$ filósofo apresenta-se como um 
especialista não especializado, mas que proporciona uma clarificação com base no conhecimento especializado. Paradoxal? Sim.

A mais valia da consultoria filosófica passa pelo facto de se desenrolar de forma a que as pessoas, neste caso os recursos humanos das $\mathrm{E} / \mathrm{O}$, ganhem autonomia no processo de pensamento. A filosofia aplicada revela aqui, como noutras áreas em que é desenvolvida, um carácter eminentemente preventivo e proactivo: não recorro ao filósofo apenas e somente quando registo um problema, mas sobretudo para explorar questões relacionadas com possíveis situações com as quais possa ser confrontado no âmbito da minha actividade profissional. A filosofia aplicada não se constitui, na sua essência, como um elemento reativo, mas dispõe de possibilidades de trabalho nesse contexto.

\section{Recomendações para o futuro}

Consideramos que o próximo passo implicará a construção e implementação de um projecto de filosofia aplicada, junto de uma empresa, para apresentação futura desse trabalho como case study. Nesse sentido, podemos aplicar o questionário aqui apresentado numa dada $\mathrm{E} / \mathrm{O}$, de forma a estudar essa realidade concreta.

Gostaríamos que o futuro nos proporcionasse a investigação da consultoria filosófica face a outras linhas dos recursos humanos, como o coaching ou o mentoring. O nosso objectivo seria o de estabelecer uma análise comparativa, procurando as suas diferenças, mas também elementos de interesse mútuo, assumindo uma perspectiva transdisciplinar.

É fundamental promover, por um lado, a investigação junto das academias; por outro lado, a divulgação de trabalhos na área da Filosofia Aplicada, de forma a desmistificar a ideia que ainda é comum: a Filosofia está condicionada à sala de aula.

Estamos confiantes de que o presente trabalho de investigação se cumpriu enquanto primeiro passo no estabelecimento de relações entre os recursos humanos e a filosofia aplicada. A partir daqui, aguarda-nos uma caminhada longa. 


\section{COMENTARIOS, INFORMES $Y$ ENTREVISTAS}

STUDIES, REPORTS AND INTERVIEWS 
